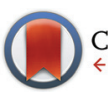

CrossMark

\&lick for updates

Cite this: Dalton Trans., 2015, 44 19411

Received 6th March 2015, Accepted 22nd April 2015

DOI: 10.1039/c5dt00914f

www.rsc.org/dalton

\section{The non-aqueous fluorolytic sol-gel synthesis of nanoscaled metal fluorides $\uparrow$}

\author{
Erhard Kemnitz* and Johannes Noack
}

\begin{abstract}
This review article focuses on the mechanism of the non-aqueous fluorolytic sol gel-synthesis of nanoscopic metal fluorides and hydroxide fluorides. Based on MAS-NMR, XRD, WAXS and SAXS investigations in combination with computational calculations, it is shown that a stepwise replacement of alkoxide by F-ions takes place resulting in the formation of a large variety of metal alkoxide fluoride clusters, some of them being isolated and structurally characterised. It is shown that these nanoscopic metal fluorides obtained via this new synthesis approach exhibit distinctly different properties compared with their classically prepared homologues. Thus, extremely strong solid Lewis acids are available which give access to new catalytic reactions with sometimes unexpectedly high conversion degrees and selectivity. Even more interestingly, metal hydroxide fluorides can be obtained via this synthesis route that are not accessible via any other approach for which the hydroxide to fluoride ratios can be adjusted over a wide range. Optically fully transparent sols obtained in this way can be used for the first time to manufacture antireflective coatings, corundum ceramics with drastically improved properties as well as novel metal fluoride based organic-inorganic composites. The properties of these new fluoride based materials are presented and discussed in context with the above mentioned new fields of application.
\end{abstract}

\section{Introduction}

Nanomaterials chemistry has become an extremely important area of research over the past 20 years. Although many different nanomaterials have already found industrial applications, we are still just at the beginning of a new scientific and industrial revolution driven by the advances in nanomaterials science.

Over the past decades, many new synthesis techniques have been developed that give access to the fascinating world of nanomaterials with different chemical and physical properties. Sol-gel synthesis is certainly one of the most powerful synthesis routes in terms of the wide variety of synthesis approaches and technical applications. For a long time, the aqueous (hydrolytic) sol-gel synthesis route in particular, mainly forced by the development of silica, was and still is in the focus of thousands of chemists and materials scientists worldwide.

However, motivated by new developments, like atomic layer deposition, ALD, and others, non-aqueous sol-gel synthesis approaches have been developed recently, thus extending the synthesis access toward nanoscopic new materials. These new

Humboldt-Universität zu Berlin, Chemistry Department, Brook-Taylor-Str. 2, D12489 Berlin, Germany.E-mail: erhard.kemnitz@chemie.hu-berlin.de

$\dagger$ Dedicated to Prof. Dr Arndt Simon on the occasion of his $75^{\text {th }}$ birthday. non-aqueous sol-gel approaches allow either the synthesis of novel materials, or in many cases give access to applications that are not possible via hydrolytic sol-gel routes. Thus, it is the intention of this review to provide an overview of a nonaqueous sol gel approach that gives for the first time direct access to novel nanoscaled metal fluorides.

Directly derived from the classical aqueous sol-gel synthesis is the non-aqueous thermally induced formation of nanoscopic metal oxides, the basics and applications of which are reflected in more detail in ref. 1. Another non-aqueous synthesis approach that lays in the focus of this review is the socalled fluorolytic sol-gel synthesis that yields nanoscopic metal fluorides in a similar variety and extent as the hydrolytic sol-gel route yields nanoscopic metal oxides. Thus, over the past few years a rapidly growing interest in nano metal fluorides has emerged from their attractive perspectives in application areas such as catalysis, optics, photonics, optical amplifiers, optoceramics, composite materials, biosensing, and biolabelling. This increasing interest in new nano fluoride based materials is clearly evidenced by the number of publications published in the past two decades. Checking the Thomson Reuters Web of Knowledge for the key words "nano" in combination with "fluoride" will retrieve just 13 publications and 96 citations for the period 1990 until 2000. Until 2005, 96 publications appeared and 1353 citations, but until 2013 as many as 750 publications and 7219 citations can be 
found! Moreover, the first book emphasizing synthesis and applications of new nano metal fluorides appeared just recently in $2010 .^{2}$

This situation has resulted in new synthesis routes toward nano metal fluorides being developed recently. Most of them will be briefly mentioned in this review but special focus will be laid on the fluorolytic sol-gel approach.

\section{The synthesis of nanoscaled metal fluorides}

Many different synthesis approaches have been developed over the past years, such as thermolysis of precursors, flame pyrolysis, reversed micelle and microemulsion precipitation, solvothermal synthesis, precipitation from non-aqueous solutions, and mechanochemical synthesis. Most of these methods were recently reviewed by Fedorov et $a l .{ }^{3}$ In fact, there are two different sol-gel based synthesis approaches, one representing a rather indirect (TFA sol-gel route) and the other a direct (fluorolytic sol-gel route) sol-gel process. Since the TFA solgel synthesis does not directly result in the formation of metal fluorides but of metal trifluoroacetate gels that might be further processed into metal fluorides after thermal degradation, this route will be reflected here just briefly, whereas the fluorolytic sol-gel synthesis resulting in direct metal fluoride formation will be discussed in more detail.

\subsection{The trifluoroacetate (TFA) sol-gel synthesis}

Probably the first synthesis method to obtain nanoscopic metal fluorides is the sol-gel derived trifluoroacetate (TFA) route, which has been established for the preparation of high specific surface area metal fluoride catalysts, fluoride glasses and thin metal oxide fluoride films of defined thickness and refractive index.

It has been found that even though fluorine is strongly bound in the $\mathrm{CF}_{3}$-group, certain metal trifluoroacetates can be thermally decomposed to form the corresponding metal fluorides. First studies investigated the preparation of lanthanide fluorides ${ }^{4}$ heavy-metal ZBLAN fluoride glasses ${ }^{5}$ by thermal decomposition of zirconium, barium, lanthanum, aluminium and sodium trifluoroacetates at temperatures between 220 and $300{ }^{\circ} \mathrm{C}$. Later, that principle was extended to other metals, especially alkaline earth ${ }^{6}$ and rare-earth metal fluorides. ${ }^{6 d, 7}$ In addition, complex metal fluorides are accessible by the TFA route. ${ }^{8}$ Recently, several metal fluoride catalysts $\left(\mathrm{MgF}_{2}, \mathrm{BaF}_{2}\right.$, $\mathrm{CaF}_{2}, \mathrm{ZnF}_{2}, \mathrm{LaF}_{3}$ and $\mathrm{CeF}_{3}$ ) with high specific surface areas between 20 and $125 \mathrm{~m}^{2} \mathrm{~g}^{-1}$ have been synthesized by thermal decomposition of metal trifluoroacetates. ${ }^{9}$

The chemical principle of the TFA route mainly developed by Fujihara et al. ${ }^{10}$ consists of the reaction of a metal alkoxide or acetate with trifluoroacetic acid in an organic, mainly alcoholic, solvent ( $c f$. eqn (1)).

$$
\mathrm{M}(\mathrm{OR})_{n}+n \mathrm{CF}_{3} \mathrm{COOH} \rightarrow \mathrm{M}\left(\mathrm{OOCCF}_{3}\right)_{n}+n \mathrm{ROH}
$$

Due to the electron-withdrawing $\mathrm{CF}_{3}$-group, TFA is strongly acidic and substitutes the acetate or alkoxide group from the coordination of the metals. As a result, a metal trifluoroacetate sol may form, which can be further processed, e.g. for coating $^{10}$ or powder materials. Crystalline metal fluorides are formed by thermal decomposition of the trifluoroacetate sols and gels during calcination at temperatures up to $400{ }^{\circ} \mathrm{C}$. At higher temperatures, oxide fluorides and oxides can also be formed as additional phases. ${ }^{6 d}$ In the gas phase, various fluorine species, such as $\left(\mathrm{CF}_{3} \mathrm{CO}\right)_{2} \mathrm{CO}, \mathrm{CF}_{3} \mathrm{COF}, \mathrm{COF}_{2}$, and $\mathrm{CO}_{x}$, that act as fluorinating agents have been found by MS and IR spectroscopy. ${ }^{6 e, 11}$ Recently, Mosiadz et al. reported the evidence of difluoromethylene diradicals $\left(: \mathrm{CF}_{2}\right)$ as intermediate species of the decomposition of TFA. $^{7}$ The general reaction scheme for lanthanide trifluoroacetates is given in eqn (2):

$$
\mathrm{Ln}\left(\mathrm{OOCCF}_{3}\right)_{3} \rightarrow \mathrm{LnF}_{3}+\left(\mathrm{CF}_{3} \mathrm{CO}\right)_{2} \mathrm{CO}+\mathrm{CO}_{2}+\mathrm{CO}
$$

This overall route is shown in Scheme 1 starting from metal alkoxides or acetates, which are reacted with trifluoroacetic acid in solution to form a metal trifluoroacetate precursor sol, which can be used for the preparation of thin film coatings or xerogels. The final step is the thermal decomposition of the fluoroorganic compound to give the corresponding metal fluoride. Thus, substrates to be coated are limited to those materials that are stable under the given reaction conditions.

Fig. 1 exemplarily illustrates the procedure for sol-gel deposition of a porous $\mathrm{MgF}_{2}$ film on silicon substrates by the TFA route. $^{6 a}$ The $\mathrm{Mg}\left(\mathrm{CF}_{3} \mathrm{COO}\right)_{2-x}\left(\mathrm{CH}_{3} \mathrm{COO}\right)_{x}$ precursor solution that is used for thin film coating is prepared by dissolving $\mathrm{Mg}$ $\left(\mathrm{CH}_{3} \mathrm{COO}\right)_{2} \times 4 \mathrm{H}_{2} \mathrm{O}$ in an ethanol-water mixture and adding 2 equivalents of trifluoroacetic acid. Depending on the concentration, viscosity, temperature, humidity and drawing velocity, a thin film of defined thickness is deposited on the substrate by dip-coating. During drying and initial heating, solvent and excess acetic and trifluoroacetic acid evaporate and exchange processes take place, yielding mixed magnesium hydroxo acetate trifluoroacetates. At temperatures above $230{ }^{\circ} \mathrm{C}$, magnesium (oxide/hydroxide) fluorides are formed and the decomposition products of TFA are released. Crystallization of the film is observed at temperatures around $300{ }^{\circ} \mathrm{C}$, resulting in a porous thin film. The final phase composition and morphology of the film is largely determined by the applied atmosphere (humidity, gas phase composition) and heat-rate of the calcination step.

Although this was in fact the first sol-gel synthesis route leading to the formation of nanoscopic metal fluorides, several drawbacks are connected with this route. Thus, (i) not all metals form stable metal fluoroacetates, (ii) not all metal fluoroacetates decompose into metal fluorides but may also form more stable metal oxides, and (iii) even the formation of the respective metal oxide fluorides or mixtures of fluorides and oxides cannot be ruled out. Since this route demands a thermal post-treatment in any case, the suitable substrates for thin film coating are limited. Furthermore, eqn (2) is an over- 


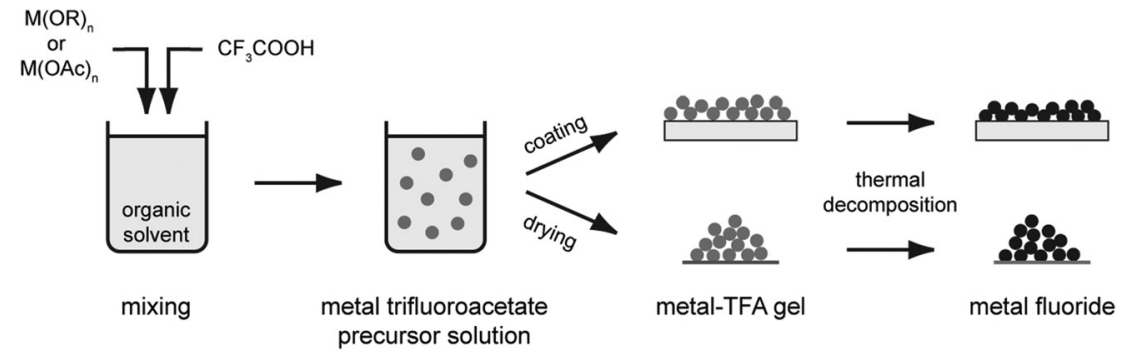

Scheme 1 Thin film and xerogel metal fluoride preparation via metal fluoroacetate sol-gel formation followed by thermal decomposition.

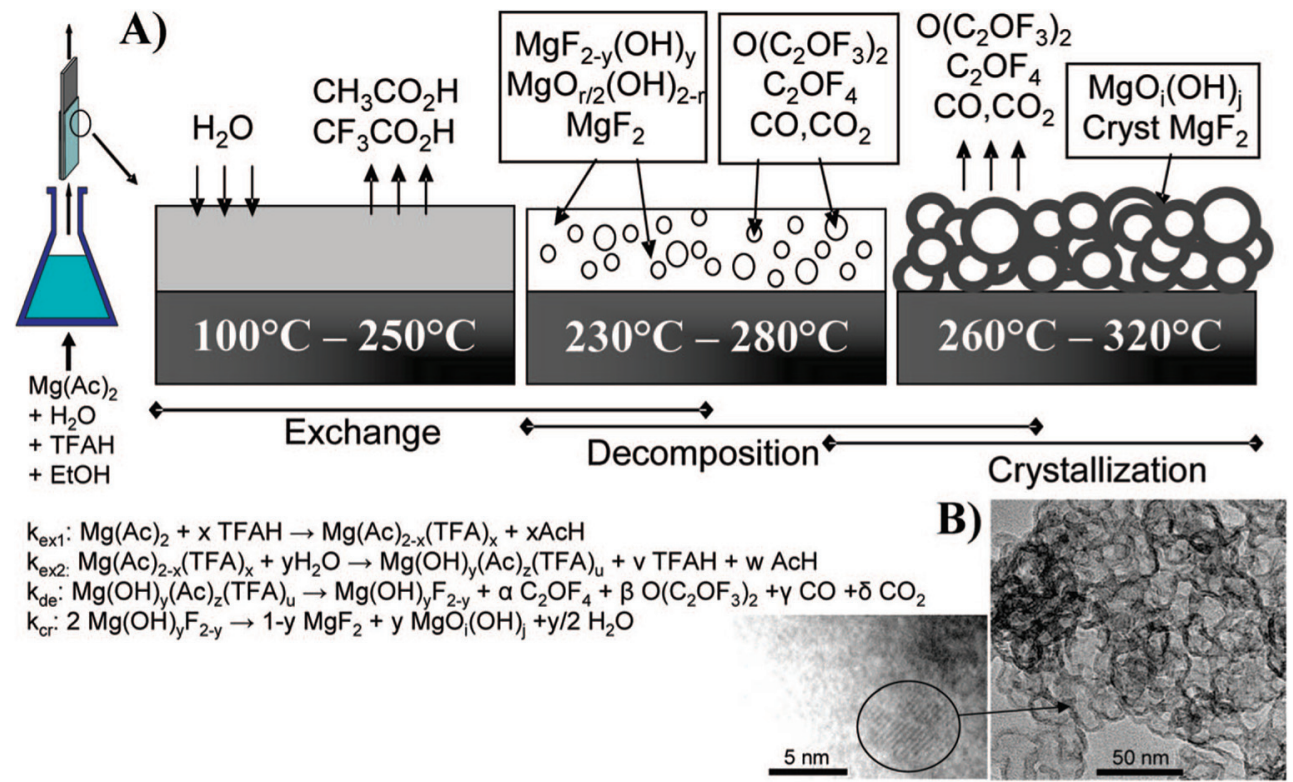

Fig. 1 (A) Scheme representing the deposition of porous $\mathrm{MgF}_{2}$ films on Si substrates by the TFA route; (B) TEM images showing the vesicle-like structures of the film prepared at $10^{\circ} \mathrm{C} \mathrm{min}-1$ under a dry atmosphere. Reprinted with permission from ref. $6 a$. $\odot 2015$ American Chemical Society.

simplification of the reaction, and the formation of highly corrosive hydrogen fluoride and other harmful decomposition products therefore has to be taken into account.

\subsection{The fluorolytic sol-gel synthesis}

In the classical sol-gel synthesis, a metal alkoxide dissolved in an organic solvent, e.g. alcohol, is reacted with water thus transforming the metal alkoxide group (M-OR) by hydrolysis into a metal hydroxide group ( $c f$. eqn (3)).

$$
\mathrm{M}(\mathrm{OR})_{n}+n \mathrm{H}_{2} \mathrm{O} \rightarrow \mathrm{M}(\mathrm{OH})_{n}+n \mathrm{ROH}
$$

In a second consecutive reaction step, $\mathrm{M}-\mathrm{OH}$ groups formed this way may undergo condensation reactions either with a further $\mathrm{M}-\mathrm{OH}$ group forming water (eqn (4)) or with an unconverted M-OR group thus elaborating alcohol (eqn (5)).

$$
\begin{aligned}
& -\mathrm{M}-\mathrm{OH}+\mathrm{HO}-\mathrm{M}-\rightarrow-\mathrm{M}-\mathrm{O}-\mathrm{M}-+\mathrm{H}_{2} \mathrm{O} \\
& -\mathrm{M}-\mathrm{OH}+\mathrm{RO}-\mathrm{M}-\rightarrow-\mathrm{M}-\mathrm{O}-\mathrm{M}-+\mathrm{ROH}
\end{aligned}
$$

Although these reactions are evidently more complex than implied by these simple reactions, the general reaction path is correctly represented. Depending on the metal alkoxides used, the hydrolysis and the condensation reactions very often are incomplete, hence, a thermal post-treatment is necessary in order to convert remaining $\mathrm{M}-\mathrm{OR}$ groups into $\mathrm{M}-\mathrm{O}-\mathrm{M}$ bridges to obtain the desired metal oxide.

Since the initial reaction step represents a hydrolysis of the metal alkoxide bond, it may be defined as hydrolytic sol-gel synthesis in order to show the similarity but also the distinct difference to the fluorolytic sol-gel synthesis that will be reflected in more detail here. As a matter of fact, both the hydrolytic as well as the non-hydrolytic sol-gel syntheses result in the formation of $\mathrm{M}-\mathrm{X}-\mathrm{M}$ (X: $\mathrm{O}$ or $\mathrm{F}$ ) bridges that - when properly performed - result in the formation of nanoscopic particles.

Formally, the fluorolytic sol-gel synthesis involves similar reaction steps as described above for the hydrolytic sol-gel 
synthesis. Starting from the same metal alkoxide precursors, water is just replaced by anhydrous HF to give eqn (6).

$$
\mathrm{M}(\mathrm{OR})_{n}+n \mathrm{HF} \rightarrow \mathrm{MF}_{n}+n \mathrm{ROH}
$$

Although eqn (6) closely resembles eqn (3), there is an important difference in that condensation reactions like those of eqn (4) and (5) are not possible in the fluoride system. However, there are very scarce examples of metal fluorides that exhibit terminal fluoride ions because fluoride ions in solid fluorides commonly tend strongly to bridge metal ions, which consequently results in the formation of well performed threedimensional metal fluoride systems. Thus, instead of condensation in the case of metal oxide formation, the strong bridging tendency of fluoride ions causes the formation of threedimensional nanoscopic particles under these conditions.

The formation of nanoscopic aluminium fluoride starting with aluminium isopropoxide ${ }^{12}$ was first and most intensively investigated regarding the underlying mechanism. ${ }^{13}$ Subsequently, a broad range of not only metal alkoxides but also carboxylates and even inorganic salts have been subjected to a sol-gel like liquid phase fluorination with hydrogen fluoride in organic solution. ${ }^{13 e, 14}$ Although the reaction conditions differ-sometimes drastically-from one metal fluoride system to another, the general synthesis path of the fluorolytic sol-gel synthesis is comparable and may be summarized as shown in Scheme 2.

In general, the metal alkoxide or any other suitable precursor is dissolved in an alcohol or any other suitable organic solvent (left side, in Scheme 2). A solution of anhydrous hydrogen fluoride in, e.g. alcohol or ether is added in about stoichiometric amounts to the precursor solution, resulting in a clear, translucent sol (temperature range $100-250{ }^{\circ} \mathrm{C}$ ), which may become a gel, depending on the concentration, type of precursor and solvent $\left(230-280^{\circ} \mathrm{C}\right)$. Varying the alkoxide from methoxide, ethoxide, isopropoxide or butoxide does not markedly affect the outcome of the fluorolytic reaction. ${ }^{13 c}$

Since the metal fluoride xerogels obtained after solvent removal $\left(260-320^{\circ} \mathrm{C}\right)$ may contain some remaining organic

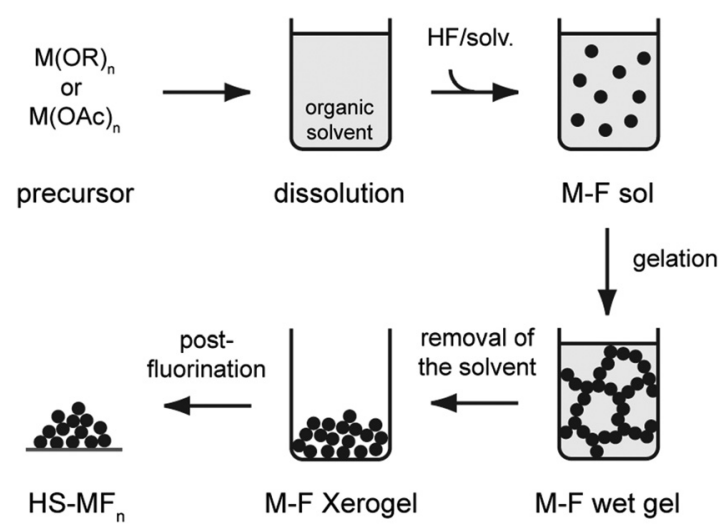

Scheme 2 Illustration of the fluorolytic sol-gel synthesis starting from a metal alkoxide or carboxylate. compounds, being either un-converted organic groups bound to the metal or trapped solvent molecules, organic free, high surface (HS) metal fluorides xerogels can be obtained by a thermal post-treatment (step 5) employing either gaseous HF or chlorofluorocarbons such as $\mathrm{CCl}_{2} \mathrm{~F}_{2}$ or $\mathrm{CHClF}_{2}$ as fluorinating agents. ${ }^{13 e}$

In recent years, much work has been done on adapting the fluorolytic sol-gel chemistry to other metals. ${ }^{15}$ In the attempt to get deeper insights regarding the mechanism of the fluorolytic sol-gel synthesis, most efforts have been made in the cases of $\mathrm{AlF}_{3}$ and $\mathrm{MgF}_{2}$ formation. Hence, the following subchapters will focus on different mechanistic aspects derived from these two metal fluoride systems.

\subsubsection{Mechanistic aspects of the fluorolytic sol-gel} synthesis

NMR investigation of the formation of $\mathrm{AlF}_{3}$ from $\mathrm{Al}(\mathrm{OiPr})_{3}$ and $H F$. Most metal fluorides obtained by fluorolytic sol-gel synthesis are either totally X-ray amorphous or at least highly distorted, hence, diffraction methods are often inappropriate to follow the reaction path. Although other methods, such as FT-IR, Raman or TEM, give valuable data for the final products, for a detailed insight into the mechanism of the fluorolytic sol-gel process, NMR spectroscopy has been found to be the method of choice. Both liquid and solid state NMR investigations allow direct observations of local structures and their changes, even if the matrices suffer from a lack of lattice periodicity. For the fluorolytic sol-gel process both liquid and solid state NMR experiments were performed including ${ }^{1} \mathrm{H},{ }^{13} \mathrm{C},{ }^{27} \mathrm{Al}$ and ${ }^{19} \mathrm{~F}$ as sensitive spin probes. The use of $1 \mathrm{D}$ and 2D NMR experiments allows local structures in liquids and solids to be addressed and directly compared. Thus, compositional and structural changes with progressive fluorination degrees were followed and finally a possible reaction pathway for this process could be derived. Due to the good experimental accessibility of the mentioned spin probes, a detailed mechanistic study was conducted for the formation of nanoscopic $\mathrm{AlF}_{3}$. These investigations were further complimented by DFT calculations.

Since for these investigations aluminium isopropoxide in isopropanol was used as the precursor, the assignment of molecular structures existing in solid $\mathrm{Al}(\mathrm{OiPr})_{3}$ and its solution in iPrOH is mandatory. In agreement with XRD findings, ${ }^{27} \mathrm{Al}$ MAS NMR measurements of solid $\mathrm{Al}(\mathrm{OiPr})_{3}$ gave an unambiguous indication of the existence of two distinguishable aluminium sites in the matrix. ${ }^{16} \mathrm{~A}$ simulation of the NMR spectra resulted in typical chemical shift values for $\mathrm{AlO}_{4}\left(\delta_{\mathrm{I}}=\right.$ $61.5 \mathrm{ppm})$ and $\mathrm{AlO}_{6}\left(\delta_{\mathrm{I}}=1.7 \mathrm{ppm}\right)$ units. ${ }^{17}$ Thus, the kind and the intensity ratio of $\mathrm{AlO}_{4}$ : $\mathrm{AlO}_{6}$ being $3: 1$ confirm the tetrameric molecular structure (see also Fig. 2, 1) existing in the tetragonal crystal structure. ${ }^{16}$

Cross-polarization $\left({ }^{1} \mathrm{H}^{-13} \mathrm{C} \mathrm{CP}\right)$ MAS NMR spectra allow distinction not only between $\mathrm{CHO}$ and $\mathrm{CH}_{3}$ groups but also between terminal $(\mathrm{Al}-\mathrm{O})$ and bridging $(\mathrm{Al}-\mathrm{O}-\mathrm{Al})$ isopropoxide units. Based on this and considering suggestions made by Abraham,${ }^{18}$ terminal (63 ppm) and bridging (66 ppm) CHO groups were found to be located in the low-field part of the 


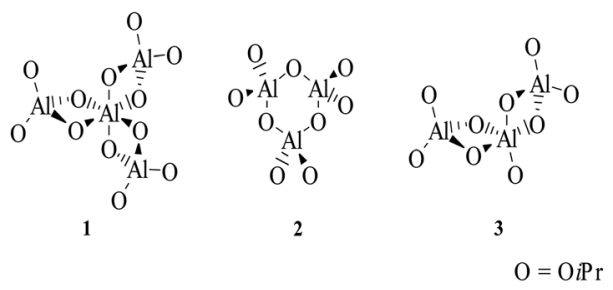

Fig. 2 Possible structural units of $\mathrm{Al}(\mathrm{OiPr})_{3}$ in solution (Reproduced from ref. 16a with permission of the American Chemical Society).

spectrum; terminal $\mathrm{CH}_{3}$ groups can be found in the range between 28-30 ppm and bridging $\mathrm{CH}_{3}$ groups dominate the high-field part of the ${ }^{1} \mathrm{H}-{ }^{13} \mathrm{C}$ CP MAS NMR spectrum. ${ }^{19}$

Because isopropanol was used as the standard solvent for the fluorolytic sol-gel synthesis, ${ }^{12-14} \mathrm{Al}(\mathrm{OiPr})_{3}$ isopropanolic solutions were carefully investigated. Whereas in etheric solutions only tetrameric aluminium isopropoxide species exist $\left(\mathrm{AlO}_{6}\right.$ (2.5 ppm, 26.7\%), $\mathrm{AlO}_{4}$ (61.8 ppm, 73.3\%), 1 in Fig. 2), the situation in isopropanolic solution is much more complex. Respective NMR investigations ${ }^{13 b}$ doubtlessly indicate not only the presence of $\mathrm{AlO}_{6}$ and $\mathrm{AlO}_{4}$ but additionally a fivefold coordinate aluminium species $\mathrm{AlO}_{5}$ at $32 \mathrm{ppm}$, thus supporting the existence of trimeric $\mathrm{Al}(\mathrm{OiPr})_{3}$ species (3 in Fig. 2).

Cyclic trimeric species ( 2 in Fig. 2) with possible distorted $\mathrm{AlO}_{4}$ polyhedra also exist, supported by a strong low-field shifted resonance observed at 85 ppm. ${ }^{13 b, 19}$ Moreover, there are indications for different trimeric species (4 and $4^{\prime}$ ) involving central sixfold oxygen-coordinate aluminium, the latter

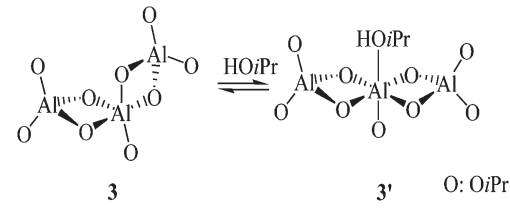

Fig. 3 Possible equilibria between different trimeric $\mathrm{Al}(\mathrm{OiPr})_{3}$ species in isopropanolic solution.

being formed by the interaction of trimeric species 3 (Fig. 2) with a solvent molecule, as shown in Fig. 3.

Structural changes of isopropanolic $\mathrm{Al}(\mathrm{OiPr})_{3}$ solutions that result from $\mathrm{HF}$ addition were followed by ${ }^{27} \mathrm{Al}$ and ${ }^{19} \mathrm{~F} \mathrm{NMR}$ spectroscopy as a function of the molar $\mathrm{Al}: \mathrm{F}$ ratio (see Fig. 4). The ${ }^{27} \mathrm{Al}$ NMR spectra reveal a decrease of $\mathrm{AlO}_{6}$ species (central $\mathrm{Al}$ of 1 in Fig. 2), as seen by the decrease of the narrow signal at $2.5 \mathrm{ppm}$ and also a decreasing proportion of the sum over all fourfold coordinated $\mathrm{Al}$ species was found. Contrary to that, fivefold coordinated aluminium species $\mathrm{AlO}_{5}$ (signals at about 35 ppm) increased. ${ }^{16 a}$

All ${ }^{19} \mathrm{~F}$ spectra are characterized by a group of three sharp signals (chemical shifts of -161 ppm, -163 ppm, -165 ppm) with different intensities. The two additional signals in (a) at $\delta_{\text {iso }}=-147 \mathrm{ppm}$ and $\delta_{\text {iso }}=-156 \mathrm{ppm}$ are, according to ref. 17, characteristic of fluorine bound to aluminium centres in a mixed oxygen-fluorine coordination, e.g. $\operatorname{AlF}_{x}(\mathrm{OiPr})_{6-x}$, with $1<$ $x<4 .{ }^{13 a, 17,20}$ The line broadening (Fig. $4,{ }^{19} \mathrm{~F}, \mathrm{~d}$ ) observed with increasing fluorine content for the peak at about $-160 \mathrm{ppm}$ is a result of ${ }^{19} \mathrm{~F}-{ }^{19} \mathrm{~F}$ homonuclear dipolar couplings ending up

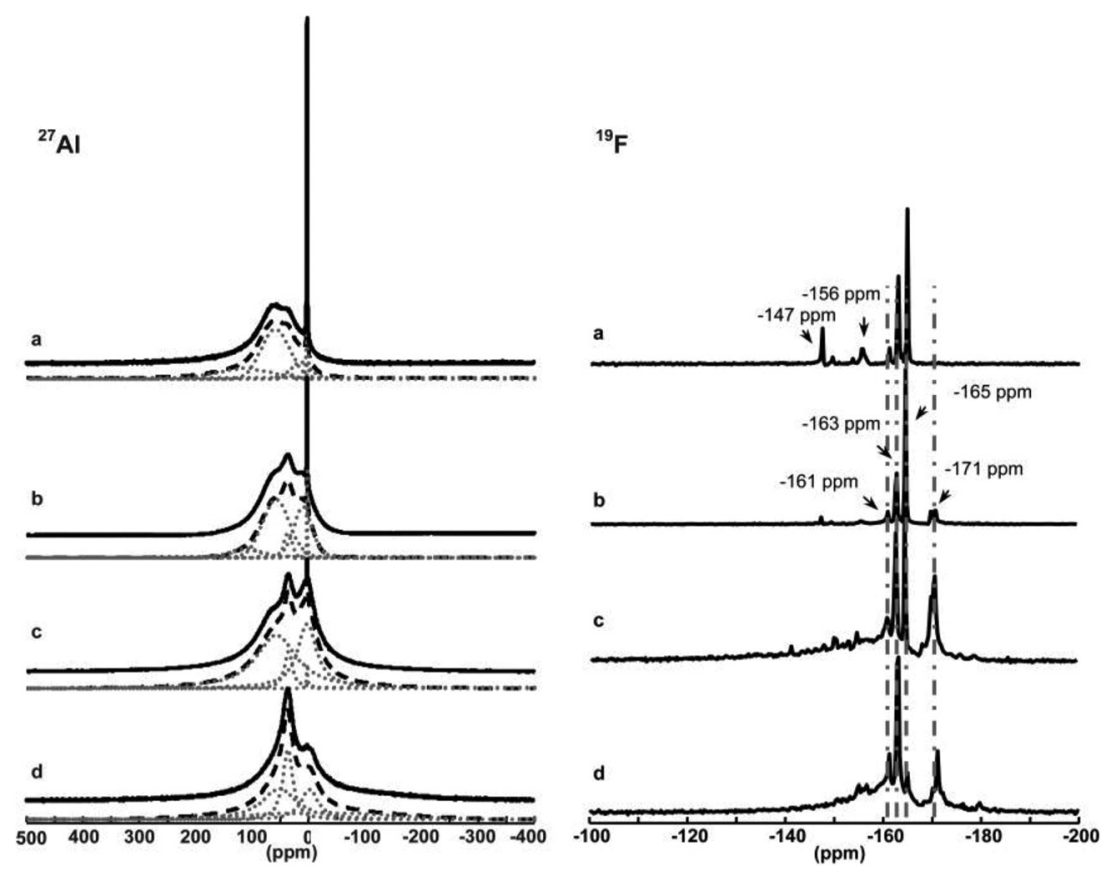

Fig. $4{ }^{27} \mathrm{Al}$ NMR and ${ }^{19} \mathrm{~F}$ NMR spectra of different sols and wet gels recorded at $B_{0}=9.4 \mathrm{~T}$. Increasing fluorine content from a-d with molar ratios Al/F: (a) $4: 1$, (b) $2: 1$, (c) $1: 1$, (d) $1: 2$ (Reproduced from ref. 16a with permission of the American Chemical Society). 


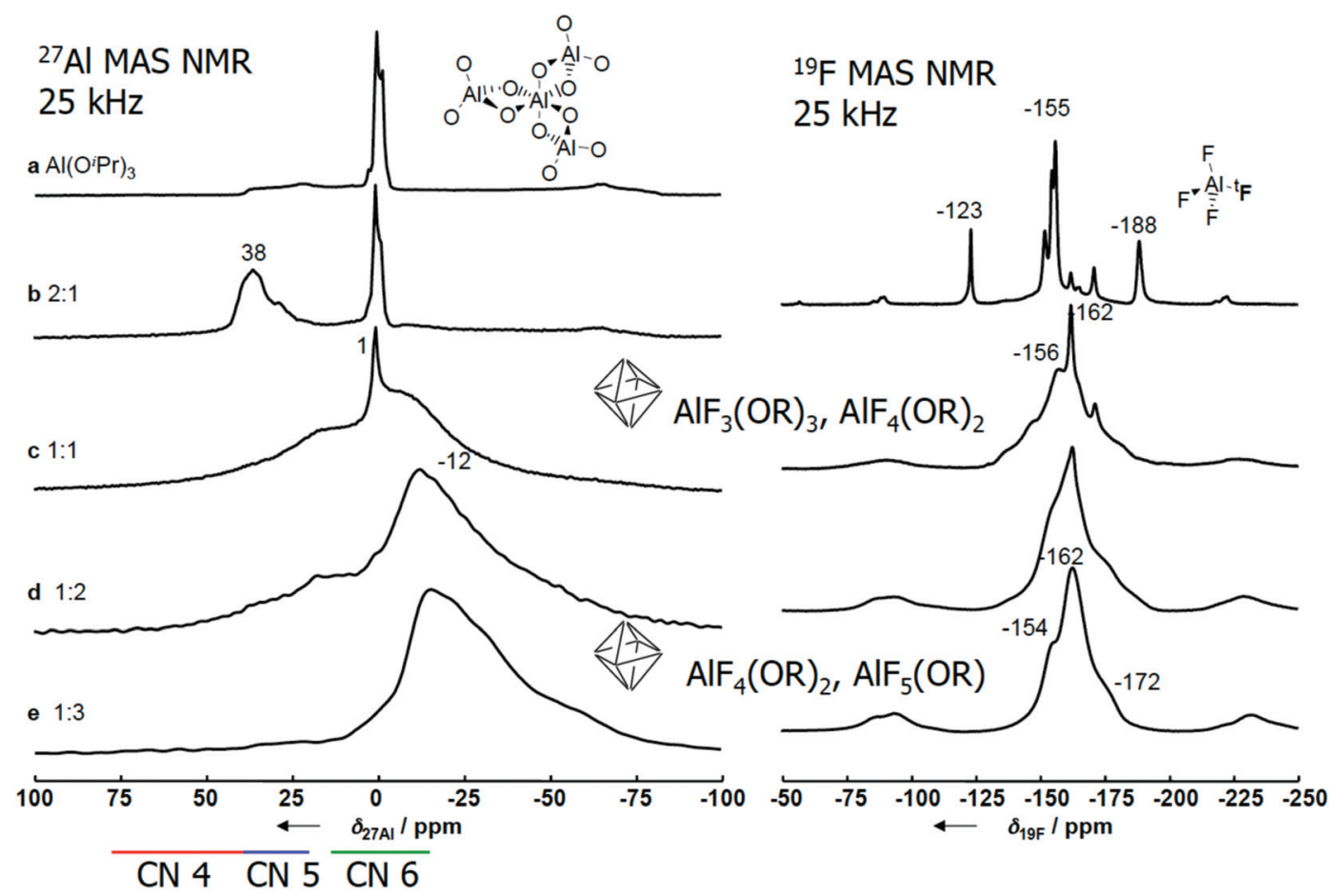

Fig. $5{ }^{27} \mathrm{Al}$ and ${ }^{19} \mathrm{~F}$ MAS NMR spectra of $\mathrm{Al}(\mathrm{OiPr})_{3}$ and aluminium isopropoxide fluoride solids prepared with different molar ratios $\mathrm{Al}: \mathrm{F}$ as given in the figure $\left(\nu_{\text {rot }}=25 \mathrm{kHz}, B_{0}=9.4 \mathrm{~T}\right)$. Reproduced from ref. $13 \mathrm{~b}$ with permission of Wiley.

in one broad peak in the static ${ }^{19} \mathrm{~F}$ NMR spectrum for the gel with molar ratio $\mathrm{Al}: \mathrm{F}$ as $1: 3$. However, these isotropic chemical shifts give no proof of the coordination number of the involved aluminium atoms.

The ${ }^{27} \mathrm{Al}$ MAS NMR spectra recorded at different magnetic fields of up to $21.1 \mathrm{~T}$ and ${ }^{27} \mathrm{Al}$ 3QMAS experimental data derived at $B_{0}=14.1 \mathrm{~T}$ enabled the simulation of the ${ }^{27} \mathrm{Al}$ MAS NMR spectra, and thus, in addition to 6-fold coordinated species, the presence of 4- and 5-fold coordinated $\mathrm{AlF}_{x}(\mathrm{OiPr})_{\mathrm{CN}-x}$ (coordination number, $\mathrm{CN}$, of 4 or 5 ) was unambiguously established for the first time for this system. ${ }^{17 b} \mathrm{~A}$ comparison of the chemical shifts observed for fluorine and aluminium isopropoxide fluorides with different $\mathrm{F}$ contents allows for a simple correlation for the appropriate species and hints of F-species connected to 4-fold and 5-fold coordinated $\mathrm{Al}$ species were corroborated. Moreover, $\mathrm{AlF}_{x} \mathrm{O}_{4-x}$ and $\mathrm{AlF}_{x} \mathrm{O}_{5-x}$ units present in the solids could be assigned based on a comprehensive ${ }^{27} \mathrm{Al}$ and ${ }^{19} \mathrm{~F}$ chemical shift trend analysis that included known chemical shifts of solids containing pure $\mathrm{AlO}_{4}, \mathrm{AlO}_{5}, \mathrm{AlF}_{4}$, and $\mathrm{AlF}_{5}$ species. ${ }^{21}$ Interestingly, the plot of the sums of the intensities of each $\mathrm{Al}$ species group (Al species with $\mathrm{CN} 4,5$, and 6) versus the increasing degree of fluorination gave three almost linear correlations. A similar plot for the $\mathrm{F}$ species was obtained by plotting the intensities of each species against the initial molar F/Al ratio. These correlations obtained are an extremely useful tool for the interpretation of ${ }^{27} \mathrm{Al}$ and ${ }^{19} \mathrm{~F}$ MAS NMR spectra of related $\mathrm{Al} / \mathrm{F} / \mathrm{O}$ systems. Based on the chemical shift trend analysis data, from ${ }^{27} \mathrm{Al}$ and ${ }^{19} \mathrm{~F}$
MAS NMR spectra taken for sols of varying Al to $\mathrm{F}$ ratios the intermediately formed $\mathrm{Al}(\mathrm{OR})_{\mathrm{CN}-x} \mathrm{~F}_{x}$-species can be unambiguously derived, as is shown in Fig. 5.

The most pronounced changes in the spectral features of ${ }^{19} \mathrm{~F}$ and ${ }^{27} \mathrm{Al}$ NMR investigation can be observed at low fluorine contents up to a molar ratio of $\mathrm{Al}$ to $\mathrm{F}$ of one (Fig. 5). Whereas the spectral features of the initial $\mathrm{Al}(\mathrm{OiPr})_{3}$ are still present in the ${ }^{27} \mathrm{Al}$ MAS NMR spectra of samples with low fluorine content, a rising signal at $38 \mathrm{ppm}$ is detected, which is provoked by a tetrahedrally coordinated aluminium site in the proximity to fluorine, as evidenced by ${ }^{19} \mathrm{~F} \rightarrow{ }^{27} \mathrm{Al} \mathrm{CP}$ MAS NMR experiments. ${ }^{13 b}$ Their ${ }^{19}$ F MAS NMR spectra (Fig. 5) are dominated by very sharp signals (FWHM less than $1 \mathrm{kHz}$ ), which indicate ordered ("crystal-like") local structures. Most of the species in these solids are more or less isolated, no proximity of the certain $\mathrm{F}$-sites to each other can be stated by ${ }^{19} \mathrm{~F}-{ }^{19} \mathrm{~F}$ spin exchange experiments. ${ }^{22}$ The 3QMAS NMR spectra of sample $\mathrm{c}$ with an $\mathrm{Al}$ to $\mathrm{F}$ ratio of $1: 1$ indicates the existence of a set of different $\mathrm{AlF}_{x}(\mathrm{OiPr})_{4-x}-\mathrm{AlF}_{x}(\mathrm{OiPr})_{5-x}$ and $\mathrm{AlF}_{x}(\mathrm{OiPr})_{6-x}$ - species (for the latter $x=3-5$ ). ${ }^{13 b}$ Those are also responsible for the remarkable line broadening effects in the corresponding fluorine spectra. The existence of defined fourfold and fivefold coordinated $\mathrm{AlF}_{x}(\mathrm{OiPr})_{\mathrm{CN}-x}$ species as intermediate structures in aluminium isopropoxide fluorides was unambiguously shown utilizing for the first time ultra high-field MAS NMR at magnetic fields $\mathrm{B}_{0}$ up to $21.1 \mathrm{~T}^{21}$

By further increasing the fluorine content $(\mathrm{Al}: \mathrm{F}$ ratios equal to $1: 2$ and $1: 3$ ), an increasingly stabilized network is 
formed. The amount and spread of four- and five-fold coordinated Al-species decreases, finally resulting in sixfold $\mathrm{AlF}_{x}(\mathrm{OiPr})_{6-x}$ species ( $x=4$ and 5$)$, as deduced from the chemical shift correlation. ${ }^{13 a, 20,23}$

A comparison of the development of the intensities of single species with rising fluorination degrees with the general development of the contributions of the appropriate ${ }^{19} \mathrm{~F}$ MAS NMR spectra allows a simple correlation of $\mathrm{Al}$ and corresponding F-species. Besides, a variety of possibly terminal fluorine-sites are evident for the highly disordered and amorphous aluminium isopropoxide fluorides in the up-field part of the spectra. ${ }^{23 a}$ In conclusion, these NMR investigations clearly evidence the stepwise fluorination of the aluminium isopropoxide with increasing HF supply during the fluorolytic sol-gel synthesis whereby the four- and five-fold coordinated Al-sites of the starting isopropoxide become completely converted into sixfold coordinated Al-sites.

In line with the conclusions drawn from ${ }^{27} \mathrm{Al}$ and ${ }^{19} \mathrm{~F}$ MAS NMR investigations are insights gained from ${ }^{1} \mathrm{H}$ and ${ }^{13} \mathrm{C}$ NMR spectra. As a rule, these ${ }^{1} \mathrm{H}$ and ${ }^{13} \mathrm{C}$ NMR spectra of sols and gels showed two main effects with increasing fluorine supply: the portion of bridging isopropoxide groups decreases while the portion of terminal isopropoxide groups is affected only with higher fluorine supply. ${ }^{16 a, 19}$

Obviously, the fluorination starts by protonation of bridging isopropoxide groups with the consequence of a line broadening of the corresponding signals, while the intensities of signals of terminal groups first remain constant. This first step is also supported by DFT calculations. ${ }^{16 a, 24}$

A subsequent step of the fluorination may involve an attack of fluorine ions or $\mathrm{HF}$, which can coordinate to central $\mathrm{Al}$ atoms of $\mathbf{1}$ and substitute the protonated isopropoxide group. During this process, central $\mathrm{AlO}_{6}$ polyhedra are more and more distorted, accompanied by a decay of the signal intensity of the central $\mathrm{Al}$ atom in $\mathbf{1}$. Moreover, a species with a slightly downfield shifted signal for mainly sixfold oxygen-coordinated $\mathrm{Al}$ atoms, as represented in Fig. 5 by the possible intermediate b, occurs. Another consequence is the rising occurrence of fivefold $\mathrm{Al}$ species (Fig. 5, b and c), which results from the former fourfold $\mathrm{AlO}_{4}$ species of $\mathbf{1}$. These first steps are also close to possible structures of intermediates as simulated with DFT calculations independently.

2.2.2. Single crystal structures of aluminium alkoxide fluorides. Because the metal fluorides obtained via the fluorolytic sol-gel synthesis are either highly distorted or even completely X-ray amorphous, diffraction methods are usually less beneficial to gain further information. Especially in the case of $\mathrm{AlF}_{3}$, it is extremely difficult to grow single crystals of intermediate species. This is mainly caused by the fact that a wide variety of oligomeric aluminium isopropoxide fluorides is present, as evidenced by mass spectrometric investigations, which prevent crystallisation. ${ }^{25}$ However, several of such intermediates were successfully crystallized from the sols as a result of pyridine or DMSO coordination to these oligomers. Although these intermediates represent only an isolated view of the structural units in the sol and are far from being quantitative, the structures of these intermediates are in total agreement with the predictions from the NMR investigations. The structures presented in Fig. 6 are sorted according to their $\mathrm{Al}$ to F stoichiometry and clearly indicate that four- and five-fold Al-sites are consumed first in the course of fluorination, finally resulting in highly fluorinated materials. The latter cannot be proven by single crystal structures because crystallization is obviously no longer favoured above a critical degree of fluorination. As has been proven by MS-investigations, ${ }^{25}$ many different partially fluorinated oligomeric/polymeric building blocks of different Al-numbers are present in such solutions. This is obviously the main reason why crystallization is sup-
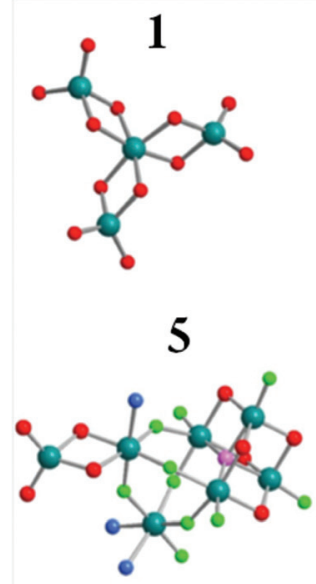

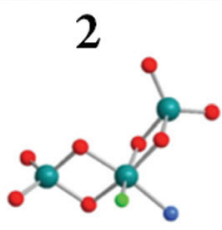

3

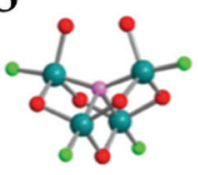

4
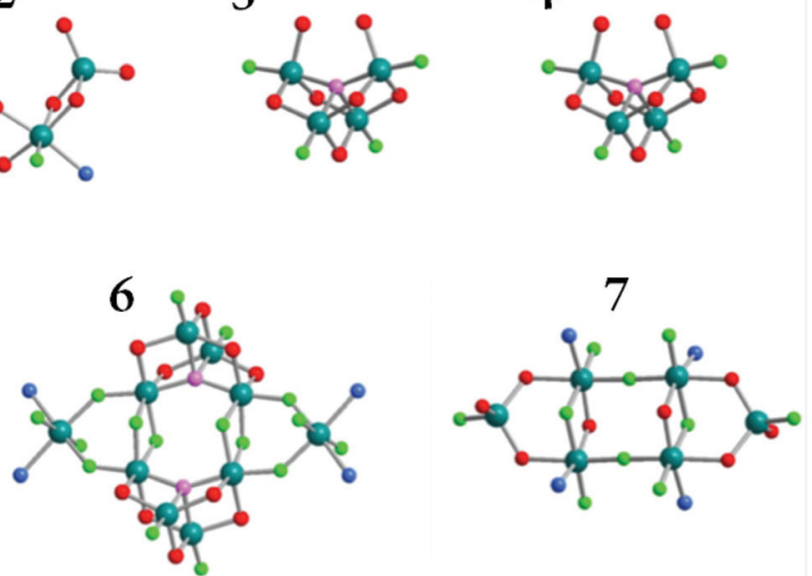

Fig. 6 Structures of aluminium alkoxide fluorides obtained from sols of varying aluminium isopropoxide to $\mathrm{HF}$ ratios sorted according to their $\mathrm{Al}$ to $F$ ratio within the structure. 1: $\mathrm{Al}_{4}(\mathrm{OiPr})_{12} ; 2: \mathrm{Al}_{3} \mathrm{~F}(\mathrm{OiPr})_{8} \cdot \mathrm{D}(\mathrm{D}=\mathrm{Py}, \mathrm{DMSO}), \mathrm{Al}: \mathrm{F}=3: 1 ; 3: \mathrm{Al}_{4} \mathrm{~F}_{4}\left(\mu_{4} \mathrm{O}\right)(\mathrm{OiPr})_{5}\left(\mathrm{H}(\mathrm{iPrO})_{2}\right), A l: F=1: 1 ; 4: A l_{5} \mathrm{~F}_{5}\left(\mu_{5} \mathrm{O}\right)(\mathrm{OiPr})_{8}$, $\mathrm{Al}: \mathrm{F}=1: 1 ; 5: \mathrm{Al}_{7} \mathrm{~F}_{10}\left(\mu_{4} \mathrm{O}\right)(\mathrm{OiPr})_{9} \cdot 3 \mathrm{Py}, \mathrm{Al}: \mathrm{F}=1: 1.43 ; 6: \mathrm{Al}_{10} \mathrm{~F}_{16}\left(\mu_{4} \mathrm{O}\right)_{2}(\mathrm{OiPr})_{10} \cdot 4 \mathrm{Py}, \mathrm{Al}: \mathrm{F}=1: 1.6 ; 7: \mathrm{Al}_{6} \mathrm{~F}_{10}(\mathrm{OiPr})_{8} \cdot 4 \mathrm{Py}, \mathrm{Al}: \mathrm{F}=1: 1.67 . \mathrm{Reproduced}$ from ref. 26 with permission of the Royal Society of Chemistry. 

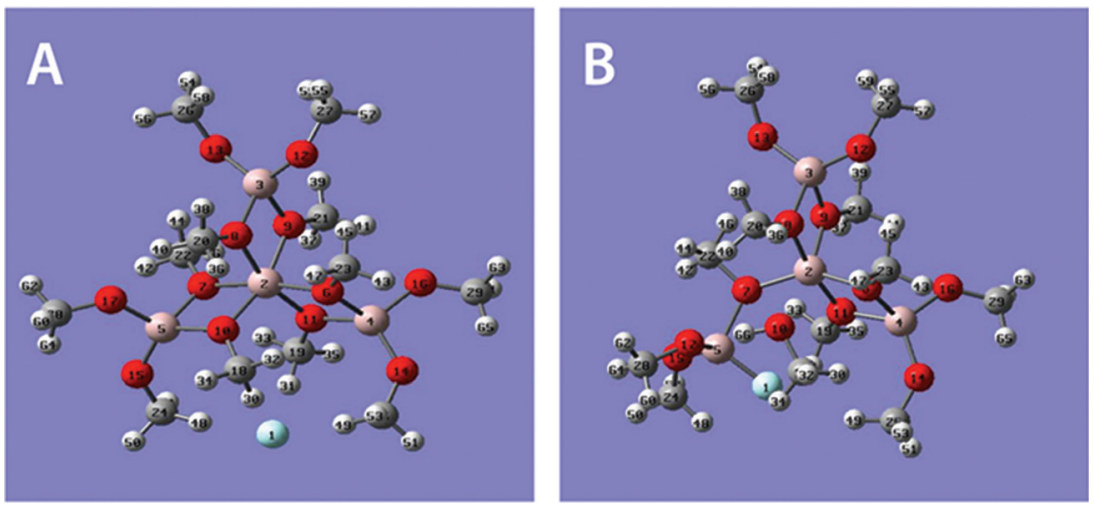

Fig. 7 DFT calculation of the first fluorination step of $\mathrm{Al}_{4}(\mathrm{OiPr})_{12}$; (a) coordination complex and (b) tetrameric unit with $\mathrm{F}^{-}$bound to $\mathrm{Al}($ peripheral), one $\mathrm{ROH}$ released, and Al(central) only 5-fold or pseudo 6-fold coordinated.

pressed. Just by addition of electron donors such as pyridine, crystallization can be enforced and thus some of these clusters underwent crystallization, thus making single crystals available. Remarkably, DFT-calculations brought about the formation of terminal fluorine bound to tetrahedrally and pentahedrally coordinated Al-sites. Although these sites were also evidenced by MAS-NMR, just a few of these terminal F-sites were found in the single crystal structures of oligomers (cf. Fig. 6). This might be rationalized by the fact that the addition of pyridine as a stabilising donor molecule might have caused some kind of rearrangement inside the aluminium alkoxide fluoride oligomers.

2.2.3. The possible reaction mechanism. Considering all these experimental findings derived from comprehensive MAS NMR and single crystal structure determination, DFT calculations were performed to show a possible mechanism of the fluorolytic sol-gel synthesis of $\mathrm{AlF}_{3}$. In order to reduce the degree of complexity, isopropoxide groups were replaced by methoxide, which can be expected to show similar reactivity and thus also being representative of the reaction of HF with $\mathrm{Al}(\mathrm{OiPr})_{3}$. Although different reaction paths have been considered, only the most probable being in accordance with the experimental data will be presented here. Since the fluorolytic sol-gel synthesis is performed in anhydrous organic solvents (usually isopropanol), tetrameric $\mathrm{Al}_{4}(\mathrm{OiPr})_{12}$ is most probably solvated. The $\mathrm{HF}$ forms oligomeric adducts of the type $\left[\mathrm{F}(\mathrm{HF})_{x}\right]^{-} \cdots[\mathrm{H} \cdots \mathrm{O}(\mathrm{H}) \mathrm{iPr}]^{+}$according to eqn (7), i.e., neither free fluoride ions nor protons are present. Similar types of HFadducts have also been reported for the HF-dimethyl ether system. ${ }^{27}$

$$
(\mathrm{HF})_{n} \rightarrow \mathrm{H}^{+}+\left[\mathrm{F}(\mathrm{HF})_{n-1}\right]^{-} \text {and } \mathrm{H}^{+}+\mathrm{HOiPr} \rightarrow \mathrm{H} \cdots \mathrm{O}(\mathrm{H}) \mathrm{iPr}
$$

Thus, in the first reaction step a HF-complex is assumed to approach the tetrameric $\mathrm{Al}_{4}(\mathrm{OiPr})_{12}$ units which might result in the coordination of fluoride ions via hydrogen bonds (Fig. 7a). Simultaneously, the proton attacks one of the four bridging $\mathrm{O}$, which are next to $\mathrm{F}$ in the complex, followed by bond cleavage of both the $\mathrm{O}$ (bridging)-Al(central) and $\mathrm{O}$ (bridging)- $\mathrm{Al}$ (peripheral) bond. This is the first ring opening of the tetramer. As a consequence, the fluoride ion will be released from the hydrogen bonding and becomes covalently bound to an $\mathrm{Al}$ (peripheral). Therein the central Al-site is no longer 6-fold coordinated by $\mathrm{O}$ but in a 5 -fold or pseudo 6 -fold coordination involving the released $\mathrm{ROH}$. The alcohol molecule which is set free remains in the vicinity of $\mathrm{Al}($ central), although it is no longer covalently bound to but probably solvating the central Al (Fig. 7b).

In the next step, the isopropanol molecule is released from the complex and due to the high electrophilic character of the central aluminium, a fluoride ion is introduced resulting in a sixfold coordinated aluminium. The alcohol molecule moves towards that $\mathrm{Al}$ (peripheral), to which the first fluoride is bound, making it pseudo 5-fold coordinated without forming a new ring (Fig. 8).

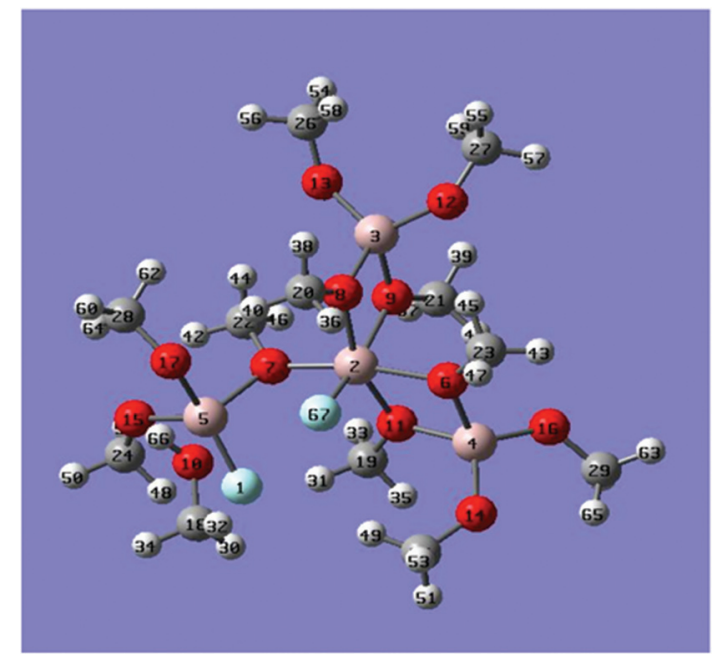

Fig. 8 A second fluoride binds to the Al(central) of the tetramer, which becomes again 6 -fold coordinated, the alcohol molecule remains in the solvating sphere of $\mathrm{Al}$ (peripheral). 

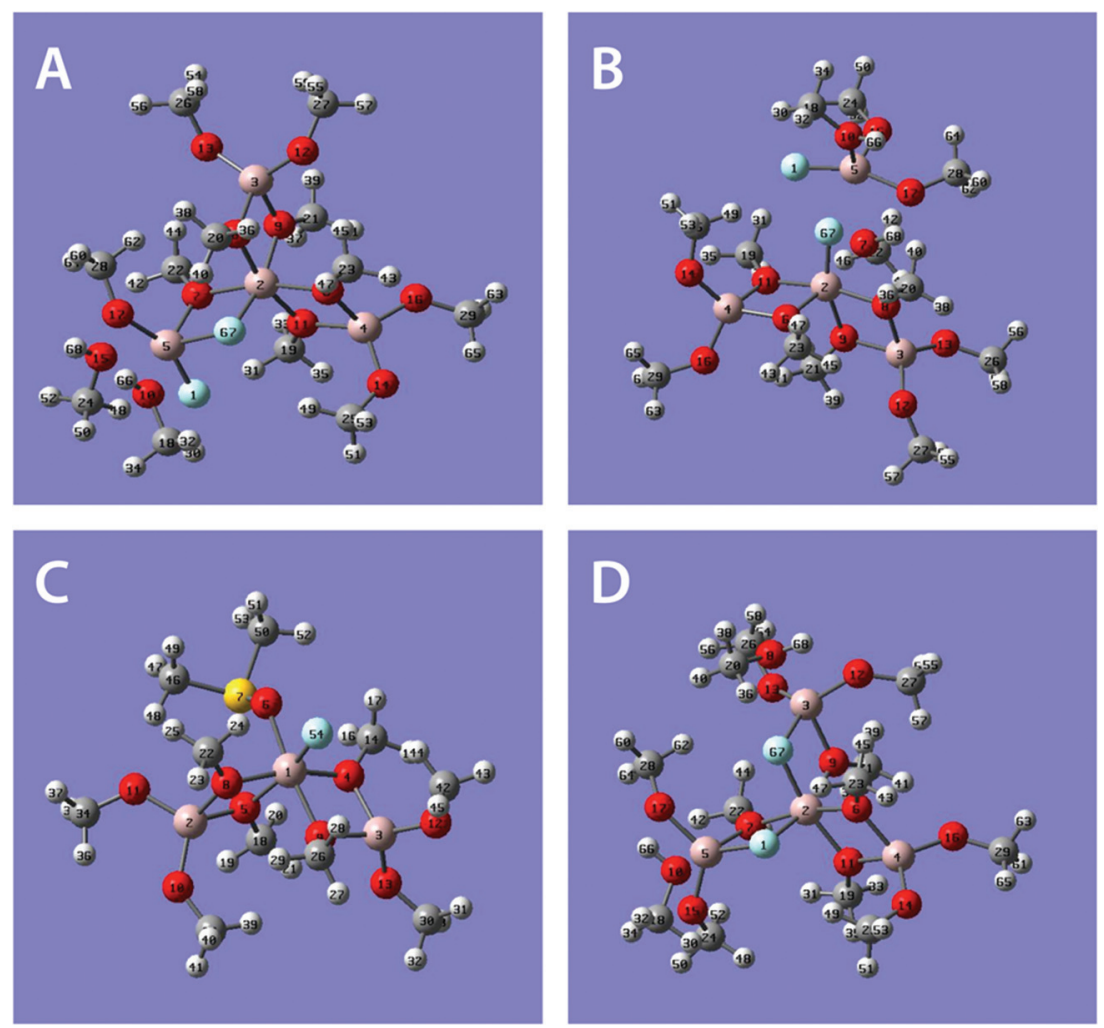

Fig. 9 (A) An F-bridged ring is closed and Al(peripheral) becomes (pseudo) 6-fold coordinated. (B) The tetramer has become cleaved forming a trimer and a monomer. (C) Calculated structure of the trimer of (B) stabilised by DMSO. (D) Tetramer containing two fluoride ions.

The protonation might occur at different positions, either (i) at the terminal, (ii) bridging oxygen atoms of the pseudo 5 -fold coordinated $\mathrm{Al}$ (peripheral) or (iii) at the bridging oxygen of the remaining two intact rings. The calculations of those three scenarios are illustrated in Fig. 9.

(i) A second alcohol molecule is set free and at the same time a new F-bridged ring is closed. Both alcohol molecules remain in the vicinity of $\mathrm{Al}$ (peripheral), which becomes pseudo 6-fold coordinated (A). This state might result in a stabilisation of the system, which is a tetramer with one $\mathrm{F}$ (bridging) and one $\mathrm{F}$ (terminal), and two alcohol molecules.

(ii) Formation of a trimer and a monomer each containing one fluorine (B) as intermediate species. Although those structures are not stable enough to be isolated, coordination of DMSO to the sixfold coordinated $\mathrm{Al}$ site has been found to increase the cluster stability. The computed structure of a DMSO-stabilized trimer (C) corresponds well to the compound that has been isolated and characterized by crystal structure analysis. $^{13 e}$ That gives indirect support for the results of the calculations and assumptions of the reaction pathway. However, the reaction should not come to a stop at this point, which is potentially in agreement with the experiment. ${ }^{12,13 e, 28}$

(iii) As a consequence of the protonation of a bridging oxygen, isopropanol is formed and another $\mathrm{O}$ (bridging)$\mathrm{Al}($ peripheral) bond is cleaved. Then two new rings, each with an $\mathrm{F}$ (bridging), are closed one after the other. The system consisting of a tetramer with two $\mathrm{F}$ (bridging) in two different rings and of two alcohol molecules may become stabilised (D).

Based on the experimental findings and computational results, Scheme 3 summarises in a simplified manner the possible reaction pathway of the fluorolytic sol-gel synthesis starting with the tetrameric $\mathrm{Al}(\mathrm{OiPr})_{3}$ and ending up in a crosslinked aluminium fluoride gel.

Mechanistic aspects of the sol-gel synthesis of $\mathrm{MgF}_{2}$. Magnesium fluoride is the second most investigated fluoride system regarding mechanistic aspects. Although in detail different, the reaction resembles in many aspects the synthesis approach as described for $\mathrm{AlF}_{3}$. Therefore, structural and topological aspects that were not followed for $\mathrm{AlF}_{3}$ will be reflected for $\mathrm{MgF}_{2}$ briefly. Different soluble precursors can be utilized for the sol-gel synthesis of magnesium fluorides. While the reaction is thermodynamically driven by the crystallization of $\mathrm{MgF}_{2}$, the reaction pathway can be different from the structure and chemical nature of the precursor. The reaction of magnesium alkoxides with HF is well investigated by NMR, IR and X-ray diffraction methods. Magnesium methoxide, which forms cubic $\left[\mathrm{Mg}_{4}\left(\mathrm{OCH}_{3}\right)_{8}\left(\mathrm{CH}_{3} \mathrm{OH}\right)_{8}\right]$ units in solution (see Fig. 10), is fluorinated at room temperature to give nanocrystalline $\mathrm{MgF}_{2}$ according to eqn (8).

$$
\mathrm{Mg}\left(\mathrm{OCH}_{3}\right)_{2}+2 \mathrm{HF} \rightarrow \mathrm{MgF}_{2}+2 \mathrm{CH}_{3} \mathrm{OH}
$$




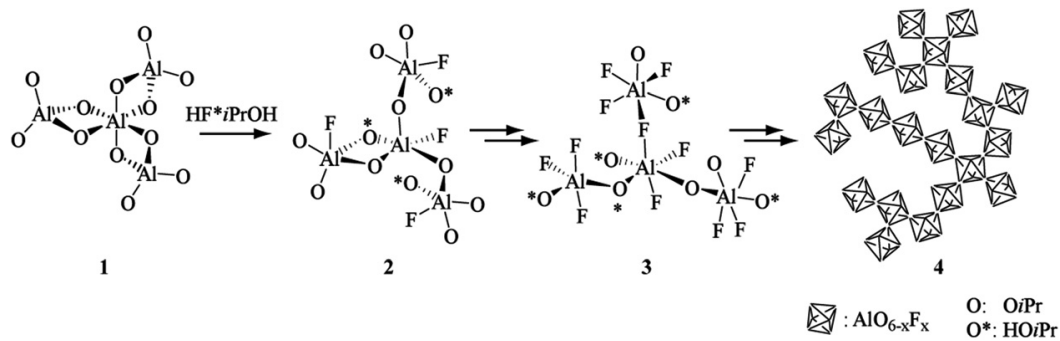

Scheme 3 Schematic representation of the formation of highly distorted nanoscopic aluminium fluoride by reacting aluminium isopropoxide with anhydrous hydrogen fluoride in isopropanol as the solvent.

a

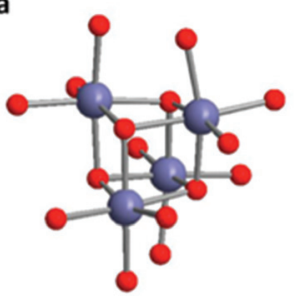

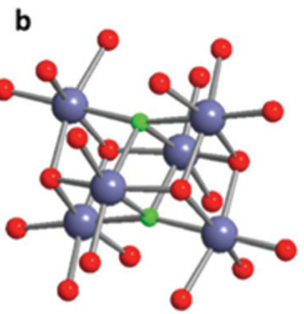

Fig. 10 Illustration of the molecular structures of magnesium methoxide (a) and the $\mathrm{Mg}_{6} \mathrm{~F}_{2}\left(\mathrm{OCH}_{3}\right)_{10}\left(\mathrm{CH}_{3} \mathrm{OH}\right)_{12}$ dicubane (b).

Similar to the sol-gel synthesis of $\mathrm{AlF}_{3}$, the formation of $\mathrm{MgF}_{2}$ proceeds via partially fluorinated species that can be isolated and characterized. The understoichiometric reaction of $\mathrm{Mg}\left(\mathrm{OCH}_{3}\right)_{2}$ with 0.1 to 0.4 equivalents of $\mathrm{HF}$ leads to partial fluorination and formation of an intermediate $\mathrm{Mg}_{6} \mathrm{~F}_{2}\left(\mathrm{OCH}_{3}\right)_{10}\left(\mathrm{CH}_{3} \mathrm{OH}\right)_{12}$ that has a dicubane structure. ${ }^{29}$ In the first step of the sol-gel reaction, methoxide groups are partially replaced by fluoride and the structure is transformed into the dicubane by addition of dimeric magnesium methoxide due to coordinatively unsaturated fluoride. Different crystalline modifications of this structure were identified by single crystal analysis $^{29 c}$ and powder diffraction, ${ }^{29 b}$ indicating its stability and relevance in the sol-gel reaction of $\mathrm{Mg}(\mathrm{OCH})_{3}$ wit HF. ${ }^{19} \mathrm{~F}$ NMR spectroscopy of the sols and xerogels shows only one signal at $-174 \mathrm{ppm}$, which is characteristic of fluorine in its $\left[\mathrm{FMg}_{4}\right]$ surrounding of the dicubane units. ${ }^{29 b, 30}$

While in contrast to the aluminium system no other intermediate species could be crystallized, XRD and ${ }^{19}$ F MAS NMR spectroscopy gave further insight into the mechanism of the fluorination and structural evolution from magnesium methoxide to $\mathrm{MgF}_{2} \cdot{ }^{29 b}$ Fig. 11a shows the X-ray powder diffraction patterns of $\mathrm{MgF}_{2-x}\left(\mathrm{OCH}_{3}\right)_{x}$ xerogels with $x=0-2$. At low $\mathrm{HF} /$ $\mathrm{Mg}$ ratios (up to 0.4 ), the diffraction patterns show rather well resolved reflections, which can be attributed to the magnesium methoxide fluoride dicubane structure in different modifications. When the fluoride content is increased, only three broad peaks are found, which reflect the formation of polymeric $\mathrm{MgF}_{2-x}\left(\mathrm{OCH}_{3}\right)_{x}$. In this structure, $\mathrm{Mg}$ is octahedrally coordinated by methoxide and fluoride to form a layered struc-
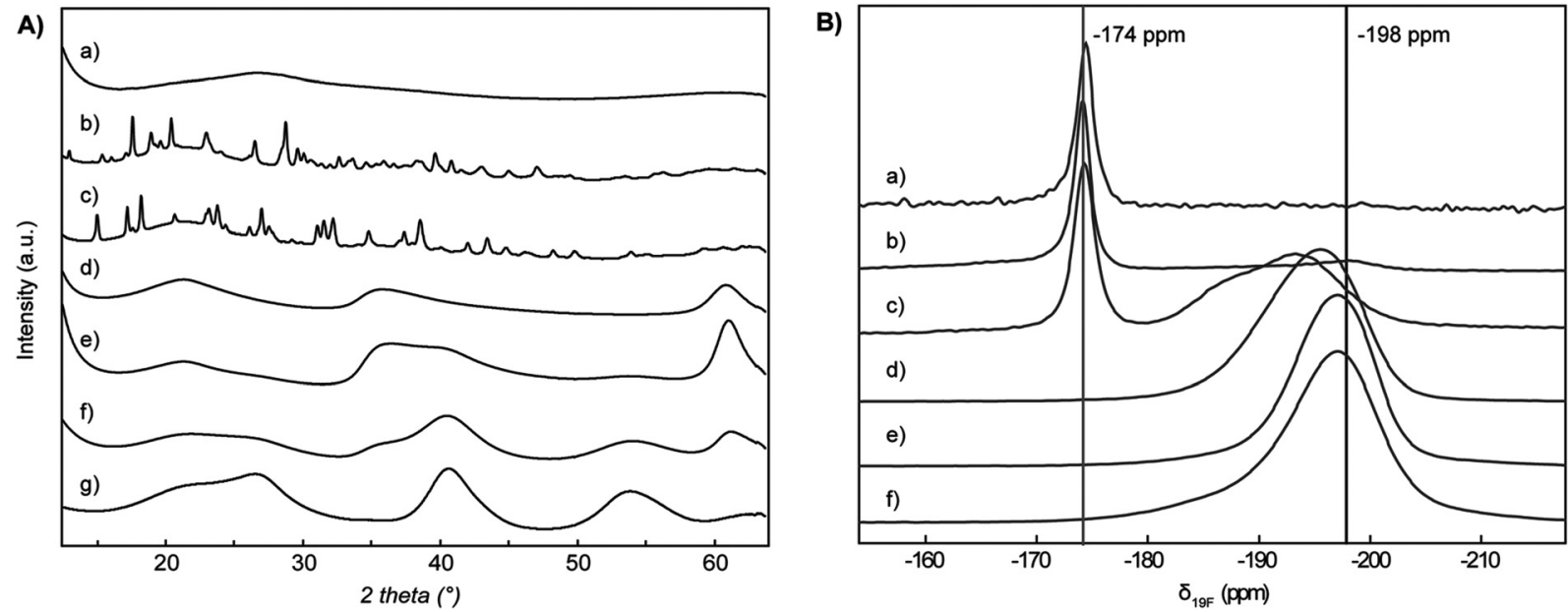

Fig. 11 (A) X-ray powder diffraction patterns of $\mathrm{MgF}_{x}\left(\mathrm{OCH}_{3}\right)_{2-x}$ with $x=0$ (a), 0.3 (b), 0.4 (c), 1 (d), 1.5 (e), 1.75 (f) and 2 (g), and (B) ${ }^{19} \mathrm{~F} \mathrm{MAS} \mathrm{NMR}$ spectra of $\mathrm{MgF}_{x}\left(\mathrm{OCH}_{3}\right)_{2-x}$ with $x=0.1$ (a), 0.3 (b), 0.4 (c), 1 (d), 1.5 (e) and 1.75 (f); recorded in a $2.5 \mathrm{~mm}$ probe at $25 \mathrm{kHz}$. Reproduced from ref. $29 \mathrm{~b}$ with permission of the Royal Society of Chemistry. 
ture as in magnesium hydroxide. Further addition of HF leads to gradual transformation from the layered into the rutile structure of $\mathrm{MgF}_{2}$ at an $\mathrm{F} / \mathrm{Mg}$-ratio of $2: 1$. These data are complemented by ${ }^{19} \mathrm{~F}$ MAS NMR investigations, which prove to be a valuable spin probe to deduce structural changes in the $\mathrm{Mg}$ / $\mathrm{O} / \mathrm{F}$ system as well. ${ }^{31}$ At low degrees of fluorination, the dicubane structure is also found as the main intermediate species, while there are no indications for other defined molecular intermediates. The ${ }^{19} \mathrm{~F}$ chemical shift is found to strongly depend on the local coordination environment of the fluorine atoms. During further fluorination, the ${ }^{19} \mathrm{~F}$ signal experiences a high-field shift from the dicubane at $-174 \mathrm{ppm}$ with an $\left[\mathrm{FMg}_{4}\right]$ environment up to $-185 \mathrm{ppm}$ when the number of oxygen atoms in the second order coordination sphere is decreased. This signal is further shifted to $-198 \mathrm{ppm}$ for the rutile structure of $\mathrm{MgF}_{2}$, where fluorine is in a $\left[\mathrm{FMg}_{3}\right]$ coordination. $^{31}$

The reaction yields crystalline $\mathrm{MgF}_{2}$, as seen from the XRD patterns in Fig. 11a and 12c. The reflections are very

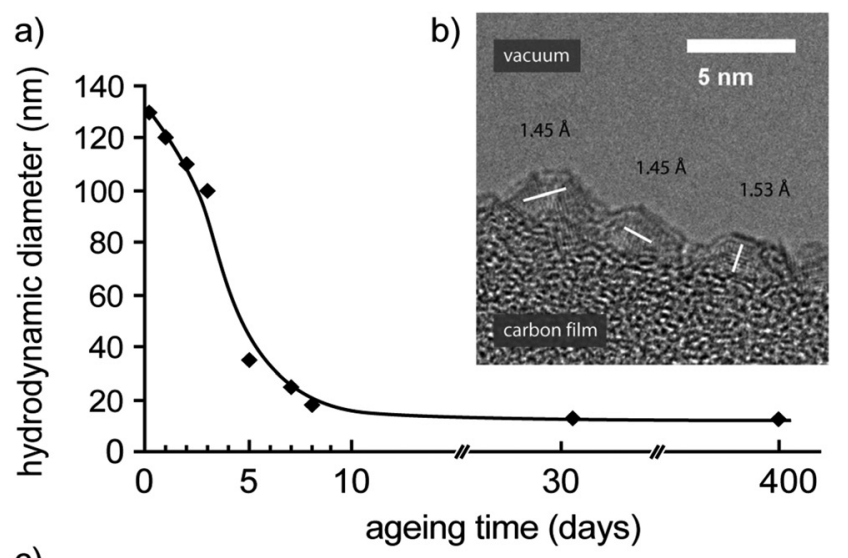

c)

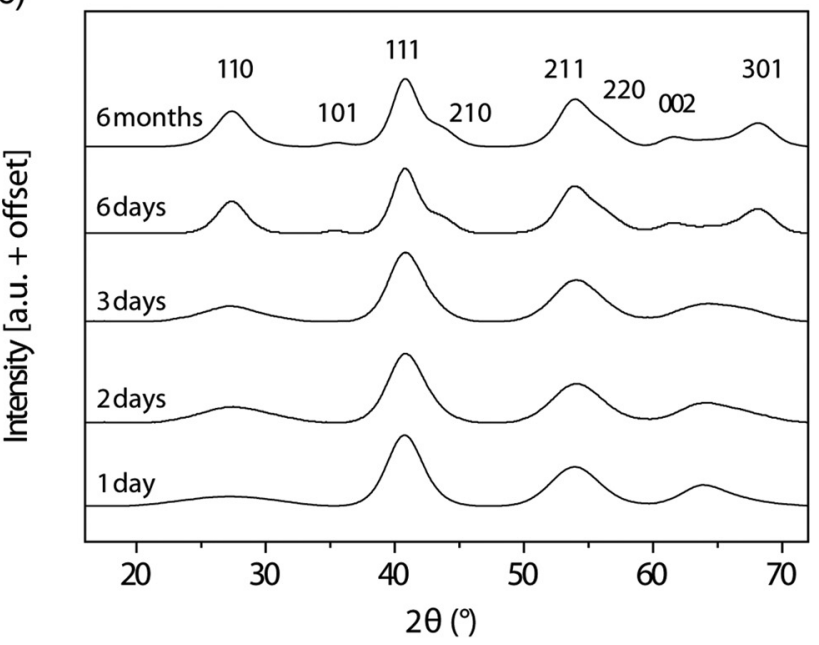

Fig. 12 Hydrodynamic diameter (a) and X-ray diffraction patterns (c) of the $\mathrm{MgF}_{2}$ particles in the sol at different ageing stages, and HR-TEM image visualising $\mathrm{MgF}_{2}$ primary particles from phosphonic acid stabilized sold (b). Reproduced from ref. $29 b$ with permission of the Royal Society of Chemistry. broad, indicating particles with a mean crystallite size of below $5 \mathrm{~nm}$. TEM images of sol particles confirm an average size of the primary particles in the range of 3 to $5 \mathrm{~nm}$ (Fig. 12c). Investigations of particles size by dynamic light scattering (DLS) and small angle X-ray scattering (SAXS) give evidence for the formation of rather large agglomerates with a diameter of a few hundred nanometers. Thus, a direct application of the fresh sols for thin film coatings or for the preparation of inorganic-organic nanocomposite materials is not possible. During ageing, the agglomerates are breaking apart, resulting in transparent sols with particles in the lower nm-scale (Fig. 12b). At the same time, re-crystallization processes are observed by X-ray diffraction methods of these sols that are closely connected to the stabilization of the primary particles and deagglomeration. This process goes in line with rearrangement of the $\mathrm{MgF}_{2}$ crystallite structure that is observed when measuring the sol at different ageing times by X-ray diffraction (Fig. 11c). Similarly as for metal oxide nano particles, magnesium fluoride sols can be surface modified and thus the stability of small particles can be significantly improved. Due to the very small particle size and thus strong interparticle interactions, the adsorption of small organic acids, such as carboxylic and phosphonic acids, has been thoroughly investigated. Proteins, such as bovine serum albumin (BSA), which are frequently used for particle stabilization in biological media, are limited because of the high volume fraction compared to the $\mathrm{MgF}_{2}$ particle. It has been found that already small amounts of trifluoroacetic acid or phenylphosphonic acid are beneficial to stabilizing magnesium fluoride particles, and prevent the sols from agglomeration and gelation. Thus, the surface properties of metal fluoride particles become addressable, which opens a new field of application and allows for the preparation of organic-inorganic composite materials.

It has been reported that the crystallization of $\mathrm{MgF}_{2}$ in different sizes and morphologies can be directed by variation of the $\mathrm{Mg} / \mathrm{F}$ ratio and concentration using alternative magnesium precursors like $\mathrm{MgCl}_{2}$ and $\mathrm{Mg}\left(\mathrm{CH}_{3} \mathrm{CO}_{2}\right)_{2}$ as well as $\mathrm{NH}_{4} \mathrm{~F}$ and $\mathrm{NaF}$ as the fluorine source. ${ }^{32}$ Yet, those reactions are far from being applicable, because of low concentrations and non-stoichiometric reactions. Recently, we demonstrated the use of $\mathrm{MgF}_{2}$ sols prepared from anhydrous magnesium chloride in dry ethanol and HF for anti-reflective coatings. ${ }^{33}$ In contrast to the reaction of magnesium methoxide with HF, which proceeds via defined intermediate molecular cubane and dicubane structures, ${ }^{19} \mathrm{~F}$ NMR spectroscopy and XRD indicate the direct formation of nanocrystalline $\mathrm{MgF}_{2}$ even at low $\mathrm{Mg} / \mathrm{F}$ ratios. Yet, the crystallite size has been found to be in a similar range to that for the reaction of $\mathrm{HF}$ with $\mathrm{Mg}\left(\mathrm{OCH}_{3}\right)_{2}$ and the sols show a much lower tendency for agglomeration and gelation. Although chloride is not evidenced in the xerogels or thin film coatings after drying and further processing, and coatings show excellent anti-reflective and mechanical properties, the technical application is rather difficult due to the high corrosive content of $\mathrm{HCl}$ formed as the result of $\mathrm{Cl}$ against $\mathrm{F}$ exchange. 


\section{Potential applications of nanoscaled metal fluorides}

\subsection{Particles and porous materials in heterogeneous catalysis}

By removing the solvents from the sols obtained via the fluorolytic sol-gel route, dry powders of nano metal fluorides will be obtained. Depending on the chemical nature of the metal, varying amounts of organic residues may still be contained in the solid materials. These can be removed by a thermal posttreatment either in inert gas atmosphere or-as in case of $\mathrm{AlF}_{3}$-in a fluorinating gas flow containing either hydrogen fluoride, or a suitable haloalkane, e.g. $\mathrm{CHClF}_{2}$ or $\mathrm{CCl}_{2} \mathrm{~F}_{2} \cdot{ }^{12,14 b, 24}$ Metal fluorides obtained this way exhibit extremely high surface areas in the range of 200 to $300 \mathrm{~m}^{2} \mathrm{~g}^{-1}$ and even higher. Because of their high surface areas, these metal fluorides are usually defined as $\mathrm{HS}_{-} \mathrm{MF}_{x}$ (HS = high surface). Due to the strong electron withdrawing effect of the fluorine environment, the high degree of structural distortion, and the large surface area, these metal fluorides exhibit extraordinarily high Lewis acidity. $\mathrm{HS}-\mathrm{AlF}_{3}$ has been found to be one of the strongest Lewis acids being comparable with $\mathrm{SbF}_{5}$ and aluminium chloride fluoride (ACF). ${ }^{34}$ CO-adsorption FT-IRinvestigations revealed the strongest Lewis acid sites ever measured at solid surfaces. ${ }^{35}$ Fig. 13 illustrates the shift of the IR-frequency of pyridine adsorbed onto $\mathrm{HS}_{-} \mathrm{AlF}_{3}$, thus indicating extremely strong Lewis acid sites at the surface, which has never been observed at any solid Lewis acid before.

As a consequence, these new metal fluoride materials are exciting catalysts for Lewis acid catalyzed reactions and were

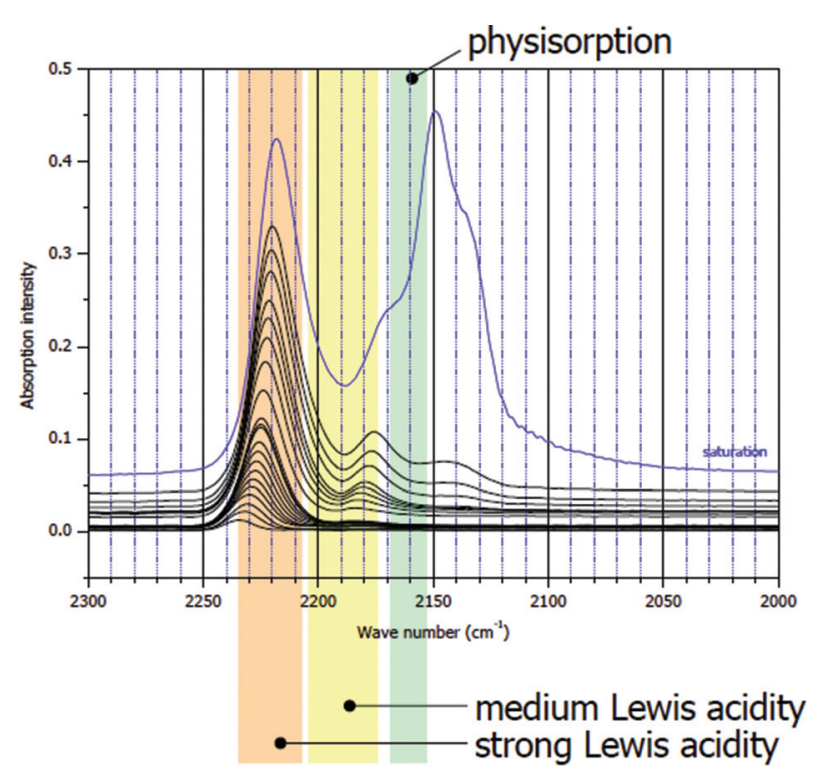

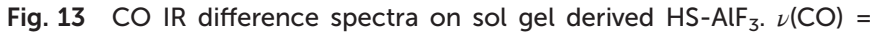
$2150 \mathrm{~cm}^{-1}$ - physisorbed $\mathrm{CO} ; \nu(\mathrm{CO})=2175 \mathrm{~cm}^{-1}-$ medium strong Lewis acid sites; $\nu(C O)=2240-2220 \mathrm{~cm}^{-1}-$ very strong Lewis acid sites. Reproduced from ref. 26 with permission of the Royal Society of Chemistry. proven to outperform even the best homogenous catalysts in some reactions. ${ }^{15 d, 36}$ A comprehensive overview of the catalytic properties of this new class of catalysts and their wide applications in different fields of catalyzed reactions can be found in a recently published review ref. 26. Therefore, just a few highlighting examples shall be given here.

Dehydrohalogenation reactions of chlorofluorocarbons give convenient access to fluoro(chloro)olefins, which are very interesting synthones for fluoropolymers. Solid Lewis acids are the choice for this kind of reaction but need temperatures between 500 and $600{ }^{\circ} \mathrm{C}$ in order to give high conversions. Since the $\mathrm{C}-\mathrm{Cl}$ bond is weaker than the $\mathrm{C}-\mathrm{F}$ bond, all classically known solid Lewis catalysts also catalyse dehydrochlorination reactions. Excitingly and uniquely, $\mathrm{HS}-\mathrm{AlF}_{3}$ was found to catalyse the dehydrofluorination reaction of 3-chloro-1,1,1,3tetrafluorobutane (eqn (9)) with $>99 \%$ conversion and 100\% selectivity exclusively toward the dehydrofluorination product at as low as $200^{\circ} \mathrm{C} .^{36 n}$

$$
\mathrm{CF}_{3}-\mathrm{CH}_{2}-\mathrm{CFCl}-\mathrm{CH}_{3} \rightarrow \mathrm{CF}_{3}-\mathrm{CH}=\mathrm{CCl}-\mathrm{CH}_{3}+\mathrm{HF}
$$

Interestingly, with nanoscopic high surface area $\mathrm{BaF}_{2}$ as the solid catalyst exclusively, the hydrodechlorination reaction (eqn (10)) was observed, giving ca. 98\% conversion and 100\% selectivity regarding the dehydrochlorination product.

$$
\mathrm{CF}_{3}-\mathrm{CH}_{2}-\mathrm{CFCl}-\mathrm{CH}_{3} \rightarrow \mathrm{CF}_{3}-\mathrm{CH}=\mathrm{CF}-\mathrm{CH}_{3}+\mathrm{HCl}
$$

Mechanistically, the contrary catalytic behaviour was discussed based on the hard and soft acids and bases (HSAB) concept. This means that the very hard Lewis acid $\mathrm{Al}^{3+}$ preferentially interacts with the very hard fluorine atom (Scheme 4, left) of the CFC, whereas the weak acidic $\mathrm{Ba}^{2+}$-surface sites preferentially interact with the weak chlorine atoms of the CFC, as rationalized in Scheme 4, right.

Another exciting example of the superior catalytic power of nanoscaled metal fluorides is the catalytic cleavage of $\mathrm{C}-\mathrm{F}$ bonds, which became possible for the first time without any precious metal and surprisingly under room temperature conditions. Thus, this became possible by creating silylium-like species at the surface of aluminium chloride fluoride (ACF) and $\mathrm{HS}_{-} \mathrm{AlF}_{3}$, as was evidenced by ${ }^{1} \mathrm{H}$ MAS NMR spectroscopy, as shown in Fig. 14c. ${ }^{36 b}$
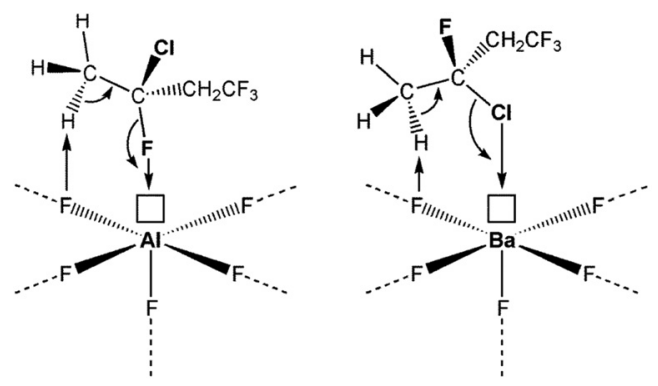

Scheme 4 Proposed catalytic mechanism for the dehydrogenation and dehydrochlorination of 3-chloro-1,1,1,3-tetrafluorobutane. Reproduced from ref. 26 with the permission of the Royal Society of Chemistry. 
A

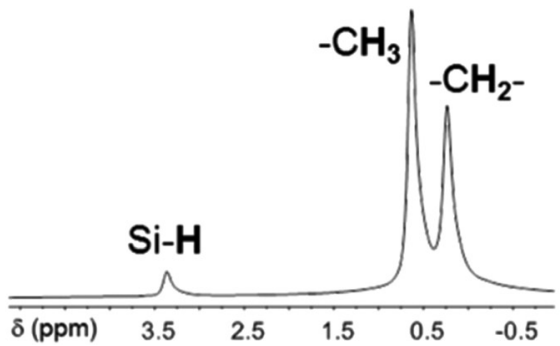

B

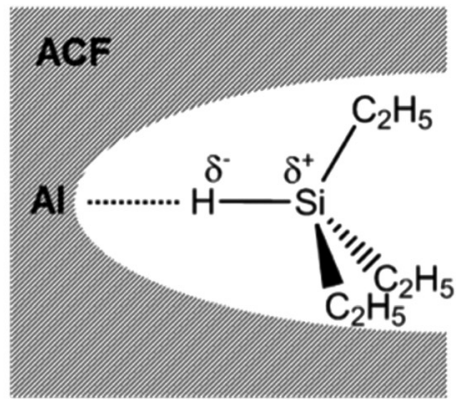

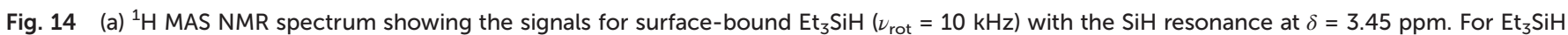

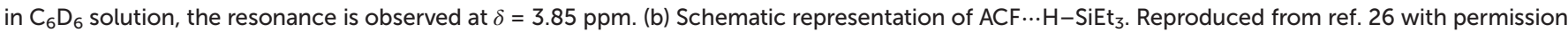
of the Royal Society of Chemistry.

On treatment of $\mathrm{CH}_{3} \mathrm{~F}, \mathrm{CH}_{2} \mathrm{~F}_{2}$, and $\mathrm{CHF}_{3}$ with these aluminium fluoride catalysts in $\mathrm{C}_{6} \mathrm{D}_{6}$ in the presence of $\mathrm{Et}_{3} \mathrm{SiH}$ at room temperature at one atmosphere, vigorous reactions and the evolution of gaseous products were observed (Fig. 15). In all these cases, formation of fully hydrogenated methane was observed for the first time under heterogeneous conditions, at low temperature and in the absence of a precious metal catalyst.

Although classically prepared $\mathrm{MgF}_{2}$ is a rather neutral compound, nanoscopic $\mathrm{MgF}_{2}$ obtained via the fluorolytic sol-gel synthesis exhibits very interesting catalytic properties. Post fluorination of the dried xerogels at $120{ }^{\circ} \mathrm{C}$ with $\mathrm{HF}$ yields nearly X-ray amorphous magnesium fluoride ( $\left.\mathrm{HS}-\mathrm{MgF}_{2}\right)$ with a specific surface area in the range of 200 to $300 \mathrm{~m}^{2} \mathrm{~g}^{-1} \cdot{ }^{34,37}$ The acid-base properties of the sol-gel $\mathrm{MgF}_{2}$ were determined by FT-IR spectroscopy and the adsorption of different probe molecules. While the adsorption of carbon monoxide shows medium to weak Lewis acid sites due to coordinatively unsaturated magnesium, we explored the basicity of surface fluorine atoms by pyrrole adsorption for the first time. ${ }^{38}$ The exciting catalytic properties of nanoscale $\mathrm{MgF}_{2}$ have been recently reviewed in ref. 39.

By combination of two or even more metals, ternary, quaternary or even more complex metal fluorides can be obtained,

a)

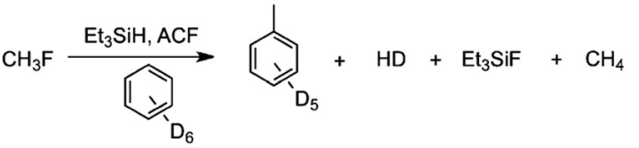

b)

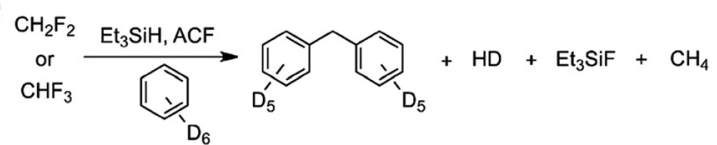

c)

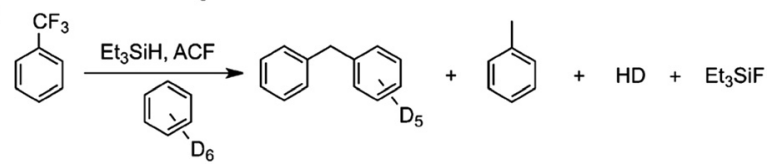

Fig. 15 ACF-catalyzed $\mathrm{C}-\mathrm{F}$ activation reactions of fluoromethanes (a and b) and trifluorotoluene (c). Reproduced from ref. $36 \mathrm{~b}$ with permission of Wiley. which allows adjustment of the optimized surface Lewis acidity over a very wide range. ${ }^{4 a}$

A further extension of this new approach results from the combination of the fluorolytic with the hydrolytic sol-gel reaction. In a first step, the fluorination is performed with understoichiometric amounts of HF resulting in an alkoxide fluoride according to eqn (11).

$$
\mathrm{M}(\mathrm{OR})_{n}+n-x \mathrm{HF} \rightarrow \mathrm{M}(\mathrm{OR})_{x} \mathrm{~F}_{n-x}+n-x \mathrm{ROH}
$$

The remaining OR-groups can be reacted with water in the second step, resulting in the formation of hydroxide fluorides (eqn (12)).

$$
\mathrm{M}(\mathrm{OR})_{x} \mathrm{~F}_{n-x}+x \mathrm{H}_{2} \mathrm{O} \rightarrow \mathrm{M}(\mathrm{OH})_{x} \mathrm{~F}_{n-x}+x \mathrm{ROH}
$$

This way, metal hydroxide fluorides are accessible in which the metal site is coordinated by both anions, hydroxide and fluoride, thus presenting real hydroxide fluorides that are almost inaccessible via any other synthesis route. ${ }^{40}$ By varying the $\mathrm{F}$ to $\mathrm{OH}$ ratio, the whole series of $\mathrm{M}(\mathrm{OH})_{x} \mathrm{~F}_{n-x}$ from $\mathrm{M}(\mathrm{OH})_{n}$ to $\mathrm{MF}_{n}$ can be synthesized. As a result, the Lewis to Brønsted acid site ratio of these materials can be tuned over a wide range resulting in optimized solid catalysts being of high interest for any kind of acid-base catalysed reactions. ${ }^{26,39}$

A slightly modified synthesis approach is the application of still stoichiometric amounts of $\mathrm{HF}$ but in the presence of water. Thus, in the presence of water the fluorolysis of the methoxide stands in direct competition with the hydrolysis. As a consequence of different reaction kinetics, e.g. magnesium hydroxide fluoride, particles with an $\mathrm{MgF}_{2}$-like structure were obtained when the sol-gel synthesis was performed with aqueous hydrofluoric acid and a $\mathrm{F} / \mathrm{Mg}$ ratio of $2: 1 .^{36 p, 41}$ The ${ }^{19}$ F MAS NMR spectra show a major signal at -198 ppm corresponding to the rutile structure of $\mathrm{MgF}_{2}$ and a broad shoulder in the lower field (-184 ppm), which evidences an oxygen-rich coordination sphere around $\left[\mathrm{FMg}_{3}\right]$ sites. FT-IR adsorption studies using $\mathrm{CO}$ and lutidine have identified Lewis acid sites of medium strength and Brønsted acidic $\mathrm{MgOH}$ sites. The latter can be explained by the electron withdrawing effect of the magnesium fluoride backbone on the hydroxyl group at 
the particle's surface. Different $\mathrm{MgF}_{2-x}(\mathrm{OH})_{x}$ phases with varying ratios of Lewis to Brønsted acidic surface sites can be obtained by variation of the HF concentration in water. ${ }^{41}$

Due to their high surface areas in combination with adjustable acid-base properties, these new materials also have great potential as catalyst support materials, as has been reported in several recent publications. ${ }^{39,41}$

\subsection{Optical materials}

This section discusses several applications of nano metal fluorides as optical materials as (i) host material for luminescent nanoparticles, (ii) transparent ceramics, and (iii) anti-reflective thin film coatings. Due to their high thermal, mechanical and chemical stability, and high transparency over a broad spectral range from the VUV to IR, metal fluorides find application in various fields of optics. Lanthanide metal doping of metal fluorides, especially complex yttrium fluoride or calcium fluoride, that act as host matrices has been intensively studied for the use in solid-state lasers. Alkaline earth metal fluoride ceramics with very high optical quality can be prepared by a hot-pressing technique, that show similar properties as single crystals. ${ }^{42}$ The fluorolytic sol-gel method gives access to the preparation of doped metal fluoride nanoparticles with luminescent properties and the synthesis of transparent ceramics of complex metal fluorides of the elpasolite type.

In the past years, the wet-chemical synthesis of rare-earthdoped calcium fluoride by precipitation methods has been reported by several groups. ${ }^{43}$ Feldmann et al. showed the stabilising effect of diethylene glycol on the formation of the nanoparticles that might be used in bio-analytical applications. ${ }^{43 c}$ The non-hydrolytic sol-gel method offers great advantages to the previously mentioned precipitation routes since it can be carried out at room temperature in large batches using standard glass vessels and usually no surfactants are required. Also great variability in the choice of precursors and solvents is given, having a direct influence on the product properties. Recently, Ritter et al. reported the sol-gel synthesis of luminescent $\mathrm{CaF}_{2}$ nanoparticle sols by the reaction of calcium lactate dissolved in methanol with anhydrous HF. ${ }^{44}$ Doping of up to $10 \mathrm{~mol} \%$ with $\mathrm{Eu}^{3+}$ and $\mathrm{Tb}^{3+}$ was achieved by addition of the lanthanide acetate before fluorination. The reaction yields fully transparent sols of crystalline $\mathrm{CaF}_{2}$ particles with a size in the lower nm-range, as seen in Fig. 16. Incorporation of the lanthanide metal ions in the $\mathrm{CaF}_{2}$ host structure can be followed both by EDX analysis and changing lattice parameters in XRD. Under illumination with $366 \mathrm{~nm}$ radiation, the sols appear in the characteristic colours (Fig. 16b) of ${ }^{5} \mathrm{D}_{0} \rightarrow{ }^{7} \mathrm{~F}_{J}$ and ${ }^{5} \mathrm{D}_{4} \rightarrow{ }^{7} \mathrm{~F}_{J}$ transitions for $\mathrm{Eu}^{3+}$ and $\mathrm{Tb}^{3+}$, respectively. Codoping of $\mathrm{CaF}_{2}$ with $\mathrm{Eu}$ and $\mathrm{Tb}$ exhibits a different emission spectrum than the physical mixture of the pure sols. ${ }^{44}$

The sol-gel synthesis can be applied for the preparation of complex metal fluorides of the types $\mathrm{MAlF}_{4}(\mathrm{M}=\mathrm{K}, \mathrm{Cs})$, $\mathrm{M}_{3} \mathrm{AlF}_{6}(\mathrm{M}=\mathrm{Li}, \mathrm{Na}, \mathrm{K})$ and $\mathrm{Na}_{5} \mathrm{Al}_{3} \mathrm{~F}_{14} \cdot{ }^{45}$ Especially doping of fluorides in the elpasolite type $\mathrm{A}_{2} \mathrm{BAlF}_{6}$ ( $\mathrm{A}$ and $\mathrm{B}=$ alkali metals) with three-valent metals ( $\mathrm{Cr}, \mathrm{Yb}, \mathrm{La}$, etc.) and their application in solid-state lasers has been investigated. ${ }^{46}$ In contrast to the earth alkaline fluorides, as-prepared $\mathrm{Rb}_{2} \mathrm{NaAlF}_{6}$ can be transformed into highly transparent ceramics by simple pressing already at low temperatures. Beside those pure metal fluoride ceramics, nanoscopic metal fluorides, especially $\mathrm{MgF}_{2}$, have recently been reported for their superior properties as sintering additive in corundum ceramic manufacturing. ${ }^{47}$ Without interfering with the technological process but just by addition of $c a .0 .1 \%$ of nanoscopic $\mathrm{MgF}_{2}$ to the starting ceramic powder, optically transparent $\mathrm{Al}_{2} \mathrm{O}_{3}$-discs can be obtained with $>70 \%$ optical transmittance. As can be seen from Fig. 17, the addition of nanoscopic $\mathrm{MgF}_{2}$ resulted in highly transparent ceramic materials. Remarkably enough, the Martens hardness, which for corundum ceramic is usually in the region of 2100 , increases significantly up to 3200 , thus corresponding to values that are characteristic for silicon carbide and/or boron nitride ceramics.

Thin films of organic and inorganic materials find wide industrial applications, e.g. in decorative and anti-reflective coatings of glass. ${ }^{48}$ Metal fluorides, especially $\mathrm{AlF}_{3}$ and $\mathrm{MgF}_{2}$, belong to the group of inorganic materials with the lowest refractive indices. Apart from the aforementioned TFA route, several methods for the deposition of thin magnesium fluoride films have been investigated in the past decades, such as physical vapour deposition (PVD), ${ }^{49}$ chemical vapour depo-
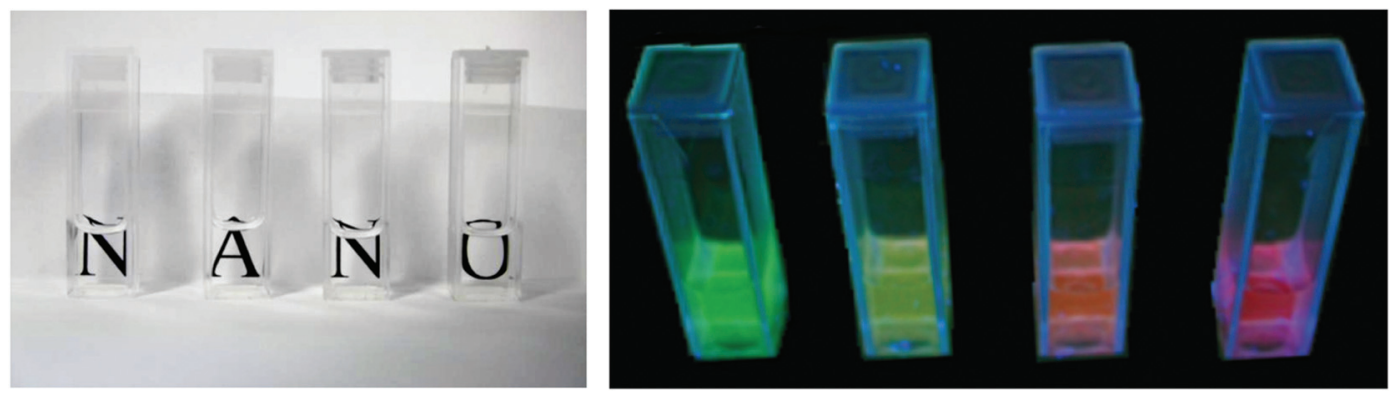

Fig. 16 Picture of transparent $\mathrm{Eu}^{3+}$ - and $\mathrm{Tb}^{3+}$-doped $\mathrm{CaF}_{2}$ sols (left) and the same sols excited with $366 \mathrm{~nm}$ (right). From left to right: $\mathrm{CaF}{ }_{2}: \mathrm{Tb}_{10}$, mixture of $52 \%$ of $\mathrm{CaF}_{2}: \mathrm{Tb}_{10}+48 \%$ of $\mathrm{CaF}_{2}: \mathrm{Eu} 10, \mathrm{CaF}_{2}: \mathrm{Tb}^{2}$.2, Eu4.8 and $\mathrm{CaF}_{2}:$ Eu10; reproduced from ref. 44 with permission of The Royal Society of Chemistry. 


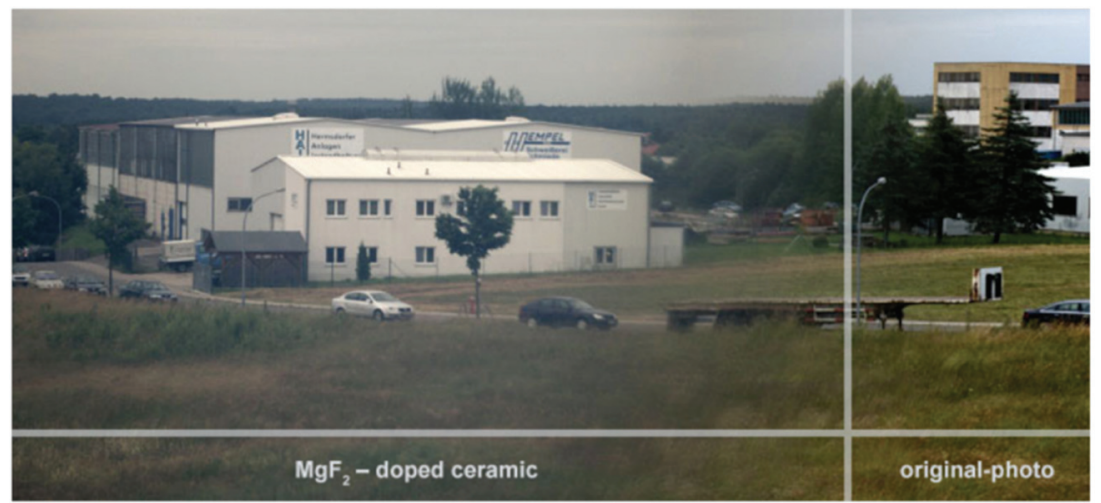

Fig. 17 Picture taken wherein the left side of the camera lens ( $2 / 3$ of the image) is covered by the "new transparent ceramic" disc whereas the right side shows the original photo.
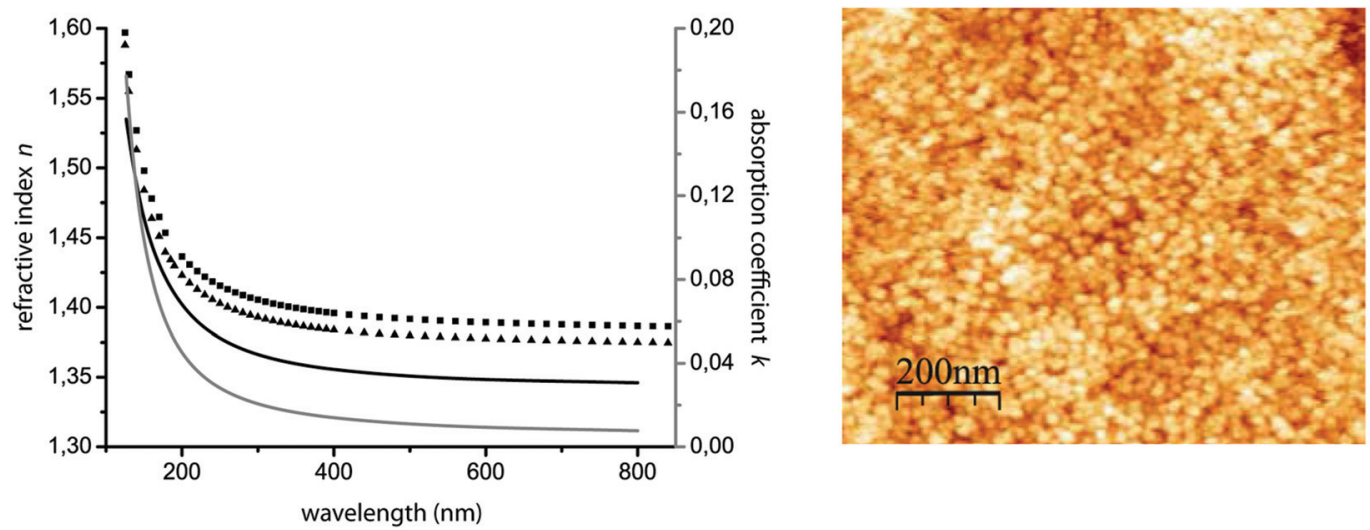

$13.5 \mathrm{~nm}$

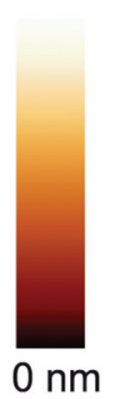

Fig. 18 Comparison of the refractive index $n$ and absorption coefficient $k$ of a $\mathrm{MgF}_{2}$-film prepared from a $0.15 \mathrm{M}$ sol on a silicon wafer (solid lines) with values from literature (squares: e-pol and triangles: o-pol) for bulk $\mathrm{MgF}_{2}{ }^{54}$ between $150 \mathrm{~nm}$ and $800 \mathrm{~nm}$ (left). AFM image of a three step coated $\mathrm{MgF}_{2}$-layer on a silicon wafer calcined at $300^{\circ} \mathrm{C}$. Reproduced from ref. $53 \mathrm{~b}$ (right) with permission of Elsevier.

sition (CVD) ${ }^{50}$ ion beam sputtering (IBS) ${ }^{49,51}$ and atomic layer deposition (ALD). ${ }^{52}$ Yet, the broad application is limited to small substrates, low deposition rate and due to the formation of highly toxic and corrosive $\mathrm{HF}$ and other fluorine species. The sol-gel method has proven to be a much more elegant route to the preparation of thin defined films with high homogeneity. ${ }^{33,53}$ Fig. 18 shows the refractive index of a film deposited on a silicon wafer by spin-coating of an $\mathrm{MgF}_{2}$ sol determined by ellipsometry in comparison to crystalline reference. As an effect of porosity inside the films, the refractive index of a sol-gel prepared $\mathrm{MgF}_{2}$ film on silicon wafers is significantly lower than that of bulk material. The AFM image (Fig. 18) of a film after coating three times confirms homogeneous surfaces with an average roughness of $1.7 \pm 0.3 \mathrm{~nm}$ consisting of nanoparticles with a diameter between $10 \mathrm{~nm}$ and $20 \mathrm{~nm} .{ }^{53 b}$ The great variability in the sol preparation and the fact that fluorine release during coating and post-treatment is effectively circumvented allow this approach for the coating of large substrates in the square meter-scales.
The anti-reflective behaviour of the coatings is clearly visualised in Fig. 19. While on the left side of the glass slide one can see the reflection of the image above, the right side is highly transparent.

As the $\mathrm{MgF}_{2}$ sols derived from the methoxide in methanol as solvent are not stable over longer time when exposed to air and tend to gelation, we recently reported about $\mathrm{MgCl}_{2}$ as a precursor in ethanol as the solvent. Thereby, the handling of toxic methanol in larger amounts and the necessity for operation under inert conditions is circumvented. ${ }^{33}$ Compared to the methanolic sol-gel synthesis, the addition of HF to the solution of magnesium chloride directly leads to the formation of nanocrystalline $\mathrm{MgF}_{2}$ with slightly increased crystallite and also particle size. Refluxing the sol leads to further crystallisation, which is directly visible in the SEM cross-section images of the film (Fig. 20). With a minimum reflectance of $0.2 \%$ at $600 \mathrm{~nm}$, the films show excellent antireflective properties, which are due to the porosity being much better than for bulk $\mathrm{MgF}_{2}$. The films exhibit superior mechanical 


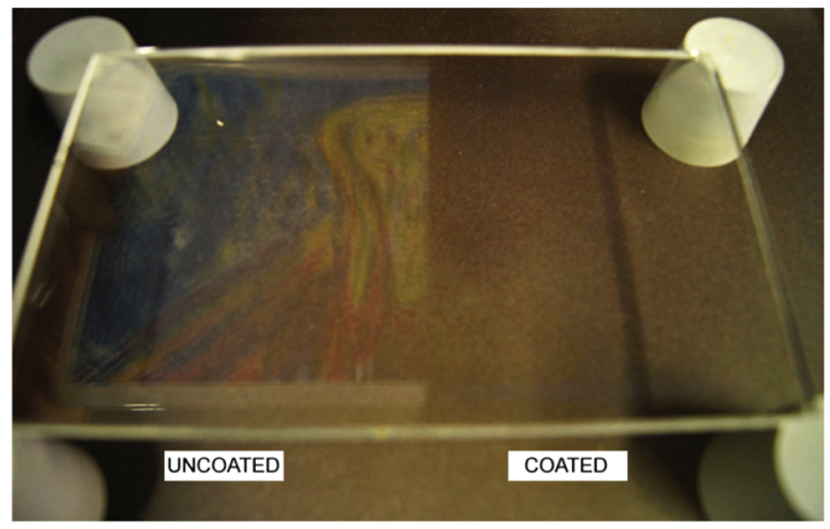

Fig. 19 Glass substrate coated by $\mathrm{MgF}_{2}$ (right) whereas the left side is untreated. An image is shown above the glass and the mirror (left) or non-mirror (right) effect of each area while taking a picture from above can be seen.

stability, as proven by the crockmeter test applying steel wool pads.

Even lower refractive indices down to 1.11 can be obtained by deliberately introducing pores into the films by templating methods. Although discussed in the context of optical applications, defined porosity also has a strong influence on the catalytic properties of materials in terms of mass-transport phenomena and product selectivity. We have shown that the nature of the template, mostly block copolymers or polymer structures, directly determines the later pore sizes and arrangement. $^{55}$

\subsection{Inorganic-organic nanocomposites}

Composite materials made by combination of inorganic nano particles and organic polymers are of high interest for materials science. Various inorganic materials have been used for the enhancement of the properties of organic polymers in

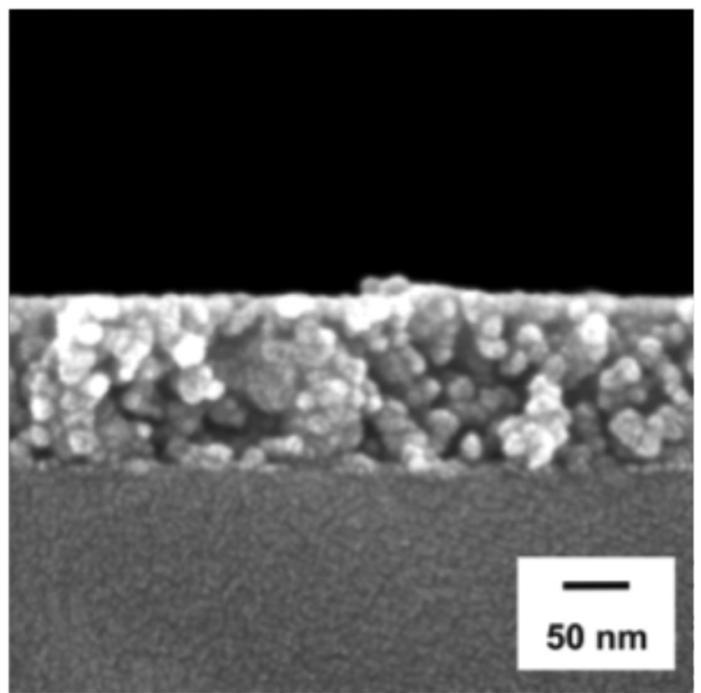

Fig. 20 Cross-sectional SEM image of $\mathrm{MgF}_{2}$ thin film annealed at $500^{\circ} \mathrm{C}$. Reproduced from ref. 33 with permission of The Royal Society of Chemistry.

terms of thermal behavior, mechanical stability and additionally new functionality to the polymer material, such as electrical or thermal conductivity or improved flame retardancy. One aspect in the use of metal fluoride fillers is their beneficial properties for optical applications. Metal fluorides, and especially magnesium and aluminium fluoride, exhibit lower refractive indices than metal oxides and can be utilized for the adjustment of the optical properties of polymers. Since the scattering of light at the filler particles strongly relates to their diameter, particles smaller than $20 \mathrm{~nm}$ have to be introduced into the polymer matrix and be effectively stabilized against agglomeration. If processed properly, optical transparent composites with a defined refractive index can be obtained, such as shown in Fig. 21 of a representative composite sample with
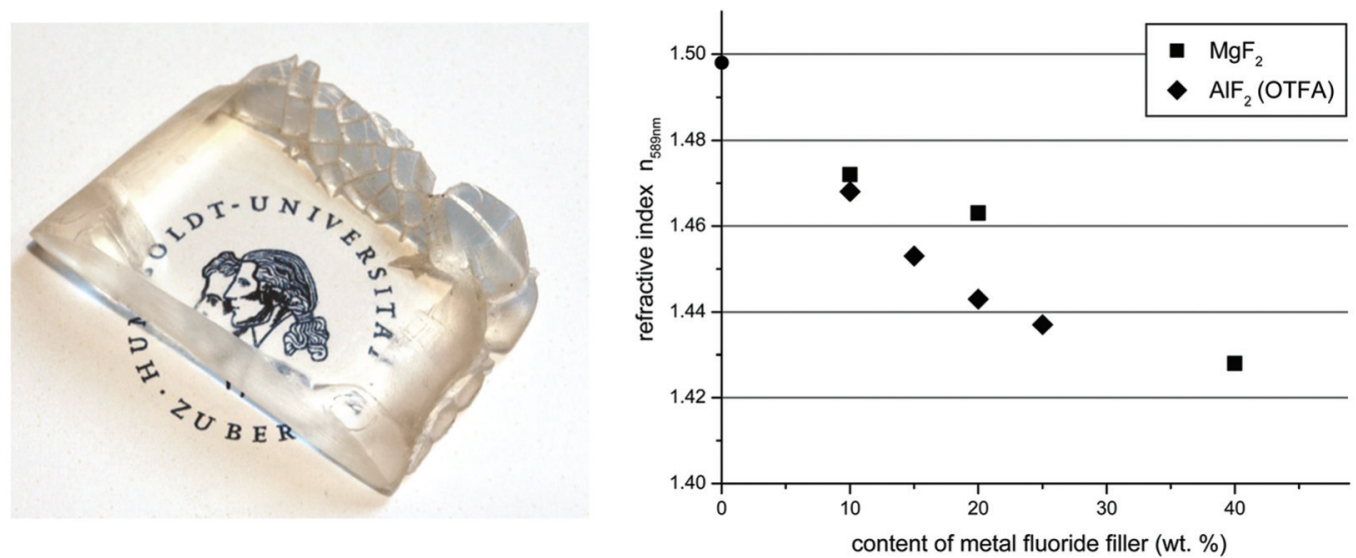

Fig. 21 Photograph of a representative composite sample with $10 \mathrm{wt} \% \mathrm{MgF}_{2}$ in a PolyHEMA matrix as bulk material (left) and refractive indices of thin film coatings based on magnesium and aluminium fluoride with different filler contents in a matrix of Poly(1,4-BDDMA) determined by ellipsometry (right). Reproduced from ref. 56 with permission of The Royal Society of Chemistry. 
$10 \mathrm{wt} \% \mathrm{MgF}_{2}$ in a PolyHEMA matrix. ${ }^{56}$ It has been shown by IR and NMR spectroscopy that trifluoroacetate strongly binds to the particle surface of magnesium ${ }^{56}$ and aluminium fluoride $^{57}$ particles and thus leads to increased compatibility between the polymer matrix and the particles. Fig. 21 illustrates the trends of decreasing refractive indices of the resulting composite films depending on the amount and type of filler material. While the pure polymer has a refractive index of 1.498 at $589 \mathrm{~nm}$ wavelength, introduction of a metal fluoride filler strongly reduces the overall refractive index of the composite. The filler material does not contribute to absorption or light scattering in the visible spectral range, as determined by ellipsometry. Since aluminium fluoride has an even lower refractive index than magnesium fluoride, the effects of its incorporation are much more pronounced. Note that porosity, which essentially accounts for the very low refractive indices of thin films, cannot be considered in the case of composites. The resulting optical constants are described by the sum of the volume fractions of individual components. ${ }^{56}$

Furthermore, the introduction of metal fluoride nanoparticles as filler material also has positive influence on the Martens hardness of the composites. ${ }^{56,58}$ For instance, introduction of $15 \mathrm{wt} \% \mathrm{MgF}_{2}$ nanoparticles stabilized by vinyl- or phenylphosphonic acid into a HDDMA polymer cause the Martens hardness (determined by microindentation) to be more than doubled from 107 to $222 \mathrm{~N} \mathrm{~nm}^{-2}$ and also the storage modulus $G^{\prime}$ raises from 2.2 to $2.8 \mathrm{Gpa}^{58}$

\section{Conclusion}

Nanoscaled metal fluorides have gained enormous interest over the past decade due to their novel properties in several fields of application. Consequently, much effort has been made to develop new synthesis approaches towards nano fluoride materials. Although several new synthesis routes have been developed, each of these suffers from at least one or even more drawbacks. The authors are convinced that the fluorolytic solgel synthesis-like the classical hydrolytic sol-gel synthesis of metal oxides-is the most powerful approach for nanoscaled metal fluorides. There are several advantages arising from this approach, which are (i) easy scale up even up to the ton-scale, (ii) resulting directly by a one-step process into monodispersed particle formation, and as a result of that, into formation of clear transparent sols, and (iii) possible processing of these sols according to already established technologies for classical metal oxide sols. The use of anhydrous hydrogen fluoride might be considered as a real drawback, however, each fluorine atom in any fluorine containing compound-no matter if inorganic or organic-originates at the very beginning of any synthesis procedure from HF that has to be used for its synthesis. That means the performance of hundreds of kilo tonnes of $\mathrm{HF}$ is state of the art for chemists specialized in fluorine chemistry in both academia and industry.

Not only pure metal fluorides, some of them exhibiting extremely strong Lewis acidity, can be obtained by reacting the metal precursor with anhydrous hydrogen fluoride but also hydroxide fluorides are accessible exclusively via this route, mainly based on two different approaches. The first one is based on using an under-stoichiometric amount of HF during the first synthesis step followed by the addition of the stoichiometrically remaining amount of water just to complete the reaction. This way, almost all nominal compositions of $\mathrm{M}(\mathrm{OH})_{n-x} \mathrm{~F}_{x}$ are accessible. However, these hydroxide fluorides can be easily transformed into the corresponding metal oxide fluorides $\left(\mathrm{MO}_{n-x / 2} \mathrm{~F}_{x}\right)$ just by post-thermal treatment. These metal hydroxide fluorides have big potential as tuneable biacidic solid catalysts, since just by tuning the oxygen to fluoride stoichiometry inside these phases, the surface acid character can be altered from strongly Lewis acidic at high F-content towards weak Lewis but stronger Brønsted acidic or even basic depending on the metal $\mathrm{M}$ at high oxygen content. Mainly determined by the $\mathrm{O}$ to $\mathrm{F}$ ratio, these oxide fluoride phases store their amorphous character (depending on the metal $\mathrm{M}$ ) up to temperatures of about $600{ }^{\circ} \mathrm{C}$ and exhibit surface areas up to $700 \mathrm{~m}^{2} \mathrm{~g}^{-1}$. It is noteworthy that some of these metal fluorides or oxide fluorides are thermally stable up to at least $1000{ }^{\circ} \mathrm{C}$, meaning no notable hydrolysis or pyrolysis reactions take place.

On the other hand, having such hydroxide fluorides in hand, the whole repertoire of chemical modifications of these nano materials as known for metal oxides can be applied in order to modify their surface, thus making them compatible with metal oxide materials, organic polymer systems, metal surfaces and many other materials systems.

The introduction of a second or even a third metal into these new compounds allows for further functionalization, resulting in unlimited new compounds with high impact on applications in catalysis, optics, sensing, up- and down conversion, electrode materials, and many others.

With this review, the authors intended to shown that these new nanoscaled metal fluoride based materials and the large variety of metal hydroxide fluorides, $\mathrm{MF}_{x}(\mathrm{OH})_{n-x}$, and metal oxide fluorides, $\mathrm{MO}_{n-x / 2} \mathrm{~F}_{x}$, phases represent a new class of materials that became accessible recently for further exploration in many different fields of application.

Of course, limitations in application may arise from chemical resistivity (hydrolysis) depending on the metal used. However, since this fluorolytic sol gel synthesis can principally be applied for most of the metals, there are many options to select appropriate metal fluorides that fulfil both requirements, being temperature stable but also hydrolysis resistant.

\section{References}

1 (a) P. H. Mutin and A. Vioux, Recent advances in the synthesis of inorganic materials via non-hydrolytic condensation and related low-temperature routes, J. Mater. Chem. A, 2013, 1(38), 11504-11512; (b) N. Pinna and M. Niederberger, Surfactant-free nonaqueous synthesis of 
metal oxide nanostructures, Angew. Chem., Int. Ed., 2008, 47(29), 5292-5304.

2 A. E. Tressaud, Functionalized Inorganic Fluorides: Synthesis, Characterization and Properties of Nanostructured Solids, John Wiley \& Sons Inc., 2010.

3 P. P. Fedorov, A. A. Luginina, S. V. Kuznetsov and V. V. Osiko, Nanofluorides, J. Fluorine Chem., 2011, 132(12), 1012-1039.

4 (a) K. W. Rillings and J. E. Roberts, A thermal study of the trifluoroacetates and pentafluoropropionates of praseodymium, samarium and erbium, Thermochim. Acta, 1974, 10(3), 285-298; (b) J. E. Roberts, Lanthanum and Neodymium Salts of Trifluoroacetic Acid, J. Am. Chem. Soc., 1961, 83(5), 1087-1088.

5 (a) C. Rüssel, A Pyrolytic Route to Fluoride Glasses .1. Preparation and Thermal-Decomposition of Metal Trifluoroacetates, J. Non-Cryst. Solids, 1993, 152(2-3), 161-166; (b) U. Wagener and C. Rüssel, A Pyrolytic Route to Fluoride Glasses .2. Preparation of Glasses in the System $\mathrm{Zrf}_{4}-\mathrm{Baf}_{2}$ $\mathrm{Laf}_{3}$-Alf $_{3}$-Naf, J. Non-Cryst. Solids, 1993, 152(2-3), 167-171.

6 (a) J. D. Bass, C. Boissiere, L. Nicole, D. Grosso and C. Sanchez, Thermally induced porosity in $\mathrm{CSD} \mathrm{MgF}_{2^{-}}$ Based optical coatings: An easy method to tune the refractive index, Chem. Mater., 2008, 20(17), 5550-5556; (b) S. Fujihara, Y. Kadota and T. Kimura, Role of organic additives in the sol-gel synthesis of porous $\mathrm{CaF}_{2}$ anti-reflective coatings, J. Sol-Gel Sci. Technol., 2002, 24(2), 147-154; (c) S. Fujihara, M. Tada and T. Kimura, Preparation and characterization of $\mathrm{MgF}_{2}$ thin film by a trifluoroacetic acid method, Thin Solid Films, 1997, 304(1-2), 252-255; (d) M. Tada, S. Fujihara and T. Kimura, Sol-gel processing and characterization of alkaline earth and rare-earth fluoride thin films, J. Mater. Res., 1999, 14(4), 1610-1616; (e) M. Mosiadz, N. L. Juda, S. C. Hopkins, J. Soloducho and B. A. Glowacki, An in-depth in situ IR study of the thermal decomposition of barium trifluoroacetate hydrate, Thermochim. Acta, 2011, 513(1-2), 33-37.

7 (a) S. Fujihara, S. Koji and T. Kimura, Structure and optical properties of $(\mathrm{Gd}, \mathrm{Eu}) \mathrm{F}_{3}$-nanocrystallized sol-gel silica films, J. Mater. Chem., 2004, 14(8), 1331-1335; (b) M. Mosiadz, K. L. Juda, S. C. Hopkins, J. Soloducho and B. A. Glowacki, An in-depth in situ IR study of the thermal decomposition of yttrium trifluoroacetate hydrate, J. Therm. Anal. Calorim., 2012, 107(2), 681-691.

8 (a) D. Boyer and R. Mahiou, Powders and coatings of LiYF4:Eu3+ obtained via an original way based on the sol-gel process, Chem. Mater., 2004, 16(13), 2518-2521; (b) S. Fujihara, Y. Kishiki and T. Kimura, Pyrolytic synthesis and $\mathrm{Eu}^{3+} \rightarrow \mathrm{Eu}^{2+}$ reduction process of blue-emitting perovskite-type $\mathrm{BaLiF}_{3}: \mathrm{Eu}$ thin films, J. Solid State Chem., 2004, 177(3), 1032-1036; (c) S. Fujihara, S. Ono, Y. Kishiki, M. Tada and T. Kimura, Sol-gel synthesis of inorganic complex fluorides using trifluoroacetic acid, J. Fluorine Chem., 2000, 105(1), 65-70.

9 A. Astruc, C. Cochon, S. Dessources, S. Celerier and S. Brunet, High specific surface area metal fluorides as cat- alysts for the fluorination of 2-chloropyridine by HF, Appl. Catal., A, 2013, 453, 20-27.

10 S. Fujihara, T. Kato and T. Kimura, Sol-Gel Processing and Luminescent Properties of Rare-Earth Oxyfluoride Materials, J. Sol-Gel Sci. Technol., 2003, 26, 953-956.

11 S. Fujihara, M. Tada and T. Kimura, Controlling factors for the conversion of trifluoroacetate sols into thin metal fluoride coatings, J. Sol-Gel Sci. Technol., 2000, 19(1-3), 311-314.

12 E. Kemnitz, U. Gross, S. Rudiger and C. S. Shekar, Amorphous metal fluorides with extraordinary high surface areas, Angew. Chem., Int. Ed., 2003, 42(35), 4251-4254.

13 (a) R. König, G. Scholz, R. Bertram and E. Kemnitz, Crystalline aluminium hydroxy fluorides - Suitable reference compounds for F-19 chemical shift trend analysis of related amorphous solids, J. Fluorine Chem., 2008, 129(7), 598-606; (b) R. König, G. Scholz and E. Kemnitz, Local Structural Changes in Aluminum Isopropoxide Fluoride Xerogels and Solids as a Consequence of the Progressive Fluorination Degree, J. Phys. Chem. C, 2009, 113(16), 6426-6438; (c) R. König, G. Scholz and E. Kemnitz, The fluorolytic solgel reaction of aluminium alkoxides: a multinuclear MAS NMR study of structural influences of the synthesis parameters, J. Sol-Gel Sci. Technol., 2010, 56(2), 145-156; (d) R. König, G. Scholz, M. Veiczi, C. Jäger, S. I. Troyanov and E. Kemnitz, New crystalline aluminum alkoxide oxide fluorides: Evidence of the mechanism of the fluorolytic solgel reaction, Dalton Trans., 2011, 40(34), 8701-8710; (e) S. K. Rüdiger, U. Gross, M. Feist, H. A. Prescott, S. C. Shekar, S. I. Troyanov and E. Kemnitz, Non-aqueous synthesis of high surface area aluminium fluoride - a mechanistic investigation, J. Mater. Chem., 2005, 15(5), 588-597; $(f)$ G. Scholz, S. Brehme, R. König, D. Heidemann and E. Kemnitz, Crystalline Aluminium Hydroxide Fluorides $\mathrm{AlF}_{x}(\mathrm{OH})_{3-x}{ }^{*} \mathrm{H}_{2} \mathrm{O}$ : Structural Insights from $1 \mathrm{H}$ and $2 \mathrm{H}$ Solid State NMR and Vibrational Spectroscopy, J. Phys. Chem. C, 2010, 114(23), 10535-10543.

14 (a) E. Kemnitz, G. Scholz and S. Rüdiger, Sol-Gel-Synthesis of Nano-Scaled Metal Fluorides - Mechanism and Properties, in Functionalized Inorganic Fluorides: Synthesis, Characterization and Properties of Nanostructured Solids, ed. A. Tressaud, John Wiley \& Sons Inc., 2010, pp. 1-35; (b) S. Rüdiger, U. Gross and E. Kemnitz, Non-aqueous solgel synthesis of nano-structured metal fluorides, J. Fluorine Chem., 2007, 128(4), 353-368.

15 (a) L. Schmidt, A. Dimitrov and E. Kemnitz, A new approach to prepare nanoscopic rare earth metal fluorides: the fluorolytic sol-gel synthesis of ytterbium fluoride, Chem. Commun., 2014, 50(50), 6613-6616; (b) L. Schmidt, F. Emmerling, H. Kirmse and E. Kemnitz, Sol-gel synthesis and characterisation of nanoscopic strontium fluoride, $R S C$ $A d v$. 2014, 4(1), 32-38; (c) L. Di Carlo, D. E. Conte, E. Kemnitz and N. Pinna, Microwave-assisted fluorolytic sol-gel route to iron fluoride nanoparticles for Li-Ion batteries, Chem. Commun., 2014, 50(4), 460-462; (d) Y. Guo, S. Wuttke, A. Vimont, M. Daturi, J. C. Lavalley, K. Teinz and 
E. Kemnitz, Novel sol-gel prepared zinc fluoride: synthesis, characterisation and acid-base sites analysis, J. Mater. Chem., 2012, 22(29), 14587-14593; (e) J. Kohl, D. Wiedemann, S. Nakhal, P. Bottke, N. Ferro, T. Bredow, E. Kemnitz, M. Wilkening, P. Heitjans and M. Lerch, Synthesis of ternary transition metal fluorides Li3MF6 via a sol-gel route as candidates for cathode materials in lithium-ion batteries, J. Mater. Chem., 2012, 22(31), 1581915827; $(f)$ A. Rehmer, K. Scheurell and E. Kemnitz, Formation of nanoscopic $\mathrm{CaF}_{2}$ via a fluorolytic sol-gel process for antireflective coatings, J. Mater. Chem. C, 2015 (3), 1716-1723.

16 (a) R. König, G. Scholz, N. H. Thong and E. Kemnitz, Local structural changes at the formation of fluoride sols and gels: A mechanistic study by multinuclear NMR spectroscopy, Chem. Mater., 2007, 19(9), 2229-2237; (b) V. J. Shiner, D. Whittaker and V. P. Fernande, Structures of Some Aluminum Alkoxides, J. Am. Chem. Soc., 1963, 85(15), 2313-2318.

17 (a) P. J. Chupas, D. R. Corbin, V. N. M. Rao, J. C. Hanson and C. P. Grey, A combined solid-state NMR and diffraction study of the structures and acidity of fluorinated aluminas: Implications for catalysis, J. Phys. Chem. B, 2003, 107(33), 8327-8336; (b) E. Kemnitz, U. Gross, S. Rudiger, G. Scholz, D. Heidemann, S. I. Troyanov, I. V. Morosov and M. H. Lemee-Cailleau, Comparative structural investigation of aluminium fluoride solvates, Solid State Sci., 2006, 8(12), 1443-1452.

18 A. Abraham, R. Prins, J. A. van Bokhoven, E. R. H. van Eck and A. P. M. Kentgens, Multinuclear solid-state high-resolution and C-13 - $\{\mathrm{Al}-27\}$ double-resonance magic-angle spinning NMR studies on aluminum alkoxides, J. Phys. Chem. B, 2006, 110(13), 6553-6560.

19 R. König, Magnetresonanzuntersuchungen zur Ausbildung lokaler Strukturen bei der Sol-Gel Synthese von Aluminiumalkoxidfluorid, Humboldt-Universität zu Berlin, Berlin, 2006.

20 (a) P. J. Chupas, M. F. Ciraolo, J. C. Hanson and C. P. Grey, In situ X-ray diffraction and solid-state NMR study of the fluorination of gamma- $\mathrm{Al}_{2} \mathrm{O}_{3}$ with $\mathrm{HCF}_{2} \mathrm{Cl}, \mathrm{J}$. Am. Chem. Soc., 2001, 123(8), 1694-1702; (b) R. König, G. Scholz, A. Pawlik, C. Jäger, B. van Rossum, H. Oschkinat and E. Kemnitz, Crystalline aluminum hydroxy fluorides: Structural insights obtained by high field solid state NMR and trend analyses, J. Phys. Chem. C, 2008, 112(40), 1570815720.

21 R. König, G. Scholz, A. Pawlik, C. Jäger, B. van Rossum and E. Kemnitz, Identification of $\operatorname{AlF}_{x}(\mathrm{OR})(\mathrm{y})$ Species in Strongly Disordered Aluminum Isopropoxide Fluoride Solids: A Field-Dependent MAS NMR Study, J. Phys. Chem. C, 2009, 113(35), 15576-15585.

22 J. K. Murthy, U. Gross, S. Rüdiger, V. V. Rao, V. V. Kumar, A. Wander, C. L. Bailey, N. M. Harrison and E. Kemnitz, Aluminum chloride as a solid is not a strong Lewis acid, J. Phys. Chem. B, 2006, 110(16), 8314-8319.

23 (a) D. Dambournet, A. Demourgues, C. Martineau, E. Durand, J. Majimel, A. Vimont, H. Leclerc, J. C. Lavalley,
M. Daturi, C. Legein, J. Y. Buzare, F. Fayon and A. Tressaud, Structural investigations and acidic properties of high surface area pyrochlore aluminium hydroxyfluoride, J. Mater. Chem., 2008, 18(21), 2483-2492; (b) D. Dambournet, A. Demourgues, C. Martineau, S. Pechev, J. Lhoste, J. Majimel, A. Vimont, J. C. Lavalley, C. Legein, J. Y. Buzare, F. Fayon and A. Tressaud, Nanostructured aluminium hydroxyfluorides derived from betaAlF3, Chem. Mater., 2008, 20(4), 1459-1469.

24 E. Kemnitz, Sol-gel-synthesis of metal fluorides - a new tool for fluoride based Materials with exciting properties, 18th Winter Fluorine Conference, St. Pete Beach, Florida, USA, 2007.

25 C. Fritz, Inorganic-organic composite systems based on nanoscopic aluminium fluoride, Humboldt-Universität zu Berlin, Berlin, 2012.

26 E. Kemnitz, Nanoscale metal fluorides: a new class of heterogeneous catalysts, Catal. Sci. Technol., 2015, 5, 786806.

27 I. Bucsi, B. Torok, A. I. Marco, G. Rasul, G. K. S. Prakash and G. A. Olah, Stable dialkyl ether/poly(hydrogen fluoride) complexes: Dimethyl ether/poly(hydrogen fluoride), a new, convenient, and effective fluorinating agent, J. Am. Chem. Soc., 2002, 124(26), 7728-7736.

28 S. Rüdiger, G. Eltanany, U. Gross and E. Kemnitz, Real solgel synthesis of catalytically active aluminium fluoride, J. Sol-Gel Sci. Technol., 2007, 41(3), 299-311.

29 (a) A. Dimitrov, S. Wuttke, S. Troyanov and E. Kemnitz, $\mathrm{Mg}_{6} \mathrm{~F}_{2}(\mathrm{OMe})(10)(\mathrm{MeOH})(14)$ - An alkoxide fluoride of an alkaline earth metal, Angew. Chem., Int. Ed., 2008, 47(1), 190-192; (b) J. Noack, F. Emmerling, H. Kirmse and E. Kemnitz, Sols of nanosized magnesium fluoride: formation and stabilisation of nanoparticles, J. Mater. Chem., 2011, 21(38), 15015-15021; (c) S. Wuttke, A. Lehmann, G. Scholz, M. Feist, A. Dimitrov, S. I. Troyanov and E. Kemnitz, Investigation of the fluorolysis of magnesium methoxide, Dalton Trans., 2009 (24), 47294734 .

30 M. Karg, G. Scholz, R. Konig and E. Kemnitz, Mechanistic insight into formation and changes of nanoparticles in $\mathrm{MgF}_{2}$ sols evidenced by liquid and solid state NMR, Dalton Trans., 2012, 41(8), 2360-2366.

31 G. Scholz, C. Stosiek, J. Noack and E. Kemnitz, Local fluorine environments in nanoscopic magnesium hydr(oxide) fluorides studied by F-19 MAS NMR, J. Fluorine Chem., 2011, 132(12), 1079-1085.

32 (a) A. B. D. Nandiyanto, F. Iskandar, T. Ogi and K. Okuyama, Nanometer to Submicrometer Magnesium Fluoride Particles with Controllable Morphology, Langmuir, 2010, 26(14), 12260-12266; (b) I. Sevonkaev and E. Matijevic, Formation of Magnesium Fluoride Particles of Different Morphologies, Langmuir, 2009, 25(18), 1053410539.

33 J. Noack, K. Scheurell, E. Kemnitz, P. Garcia-Juan, H. Rau, M. Lacroix, J. Eicher, B. Lintner, T. Sontheimer, T. Hofmann, J. Hegmann, R. Jahn and P. Löbmann, MgF2 
antireflective coatings by sol-gel processing: film preparation and thermal densification, J. Mater. Chem., 2012, 22 (35), 18535-18541.

34 J. K. Murthy, U. Gross, S. Rüdiger, E. Kemnitz and J. M. Winfield, Sol-gel-fluorination synthesis of amorphous magnesium fluoride, J. Solid State Chem., 2006, 179(3), 739-746.

35 T. Krahl, A. Vimont, G. Eltanany, M. Daturi and E. Kemnitz, Determination of the acidity of high surface $\mathrm{AlF}_{3}$ by IR spectroscopy of adsorbed $\mathrm{CO}$ probe molecules, J. Phys. Chem. C, 2007, 111(49), 18317-18325.

36 (a) I. Agirrezabal-Telleria, F. Hemmann, C. Jager, P. L. Arias and E. Kemnitz, Functionalized partially hydroxylated $\mathrm{MgF}_{2}$ as catalysts for the dehydration of d-xylose to furfural, J. Catal., 2013, 305, 81-91; (b) M. Ahrens, G. Scholz, T. Braun and E. Kemnitz, Catalytic Hydrodefluorination of Fluoromethanes at Room Temperature by Silylium-ion-like Surface Species, Angew. Chem., Int. Ed., 2013, 52(20), 53285332; (c) N. Candu, S. Wuttke, E. Kemnitz, S. M. Coman and V. I. Parvulescu, Friedel-Crafts alkylations on nanoscopic inorganic fluorides, Appl. Catal., A, 2011, 391(1-2), 169-174; (d) N. Candu, S. Wuttke, E. Kemnitz, S. M. Coman and V. I. Parvulescu, Replacing benzyl chloride with benzyl alcohol in heterogeneous catalytic benzylation of aromatic compounds, Pure Appl. Chem., 2012, 84(3), 427-437; (e) S. M. Coman, V. I. Parvulescu, S. Wuttke and E. Kemnitz, Synthesis of Vitamin K-1 and K-1-Chromanol by Friedel-Crafts Alkylation in Heterogeneous Catalysis, ChemCatChem, 2010, 2(1), 92-97; (f) S. M. Coman, P. Patil, S. Wuttke and E. Kemnitz, Cyclisation of citronellal over heterogeneous inorganic fluorides-highly chemo- and diastereoselective catalysts for (+/-)-isopulegol (pg 460, 2009), Chem. Commun., 2009 (48), 7597-7597; (g) S. M. Coman, S. Wuttke, A. Vimont, M. Daturi and E. Kemnitz, Catalytic Performance of Nanoscopic, Aluminium Trifluoride-Based Catalysts in the Synthesis of (allrac)-alpha-Tocopherol, Adv. Synth. Catal., 2008, 350(16), 2517-2524; (h) C. Dobrinescu, E. E. Iorgulescu, C. Mihailciuc, D. Macovei, S. Wuttke, E. Kemnitz, V. I. Parvulescu and S. M. Coman, One-Pot Hydroacetylation of Menadione (Vitamin K3) to Menadiol Diacetate (Vitamin K4) by Heterogeneous Catalysis, Adv. Synth. Catal., 2012, 354(7), 1301-1306; (i) O. Machynskyy, D. Lomot, K. Teinz, E. Kemnitz and Z. Karpinski, n-Pentane hydroisomerization catalyzed by metals supported on nanoscopic aluminum trifluoride, Catal. Commun., 2012, 26, 235-238; (j) A. Negoi, K. Teinz, E. Kemnitz, S. Wuttke, V. I. Parvulescu and S. M. Coman, Bifunctional Nanoscopic Catalysts for the One-Pot Synthesis of (+/-)-Menthol from Citral, Top. Catal., 2012, 55(7-10), 680687; $(k)$ A. Negoi, S. Wuttke, E. Kemnitz, D. Macovei, V. I. Parvulescu, C. M. Teodorescu and S. M. Coman, OnePot Synthesis of Menthol Catalyzed by a Highly Diastereoselective $\mathrm{Au} / \mathrm{MgF}_{2}$ Catalyst, Angew. Chem., Int. Ed., 2010, 49 (44), 8134-8138; (l) M. H. G. Prechtl, M. Teltewskoi, A. Dimitrov, E. Kemnitz and T. Braun, Catalytic C-H Bond
Activation at Nanoscale Lewis Acidic Aluminium Fluorides: H/D Exchange Reactions at Aromatic and Aliphatic Hydrocarbons, Chem. - Eur. J., 2011, 17(51), 14385-14388; (m) L. Protesescu, M. Tudorache, S. Neatu, M. N. Grecu, E. Kemnitz, P. Filip, V. I. Parvulescu and S. M. Coman, Unusual Behavior of a Novel Heterogeneous Chiral Dimer $\mathrm{Cr}(\mathrm{III})$-Salen Complex in the Epoxidation/Epoxide RingOpening Reaction of trans-Methylcinnamate Ester, J. Phys. Chem. C, 2011, 115(4), 1112-1122; (n) K. Teinz, S. Wuttke, F. Börno, J. Eicher and E. Kemnitz, Highly selective metal fluoride catalysts for the dehydrohalogenation of 3-chloro1,1,1,3-tetrafluorobutane, J. Catal., 2011, 282(1), 175-182; (o) S. B. Troncea, S. Wuttke, E. Kemnitz, S. M. Coman and V. I. Parvulescu, Hydroxylated magnesium fluorides as environmentally friendly catalysts for glycerol acetylation, Appl. Catal., B, 2011, 107(3-4), 260-267; (p) S. Wuttke, S. M. Coman, J. Kröhnert, F. C. Jentoft and E. Kemnitz, Solgel prepared nanoscopic metal fluorides - a new class of tunable acid-base catalysts, Catal. Today, 2010, 152(1-4), 2-10; (q) S. Wuttke, A. Negoi, N. Gheorghe, V. Kuncser, E. Kemnitz, V. Parvulescu and S. M. Coman, Sn-Doped Hydroxylated $\mathrm{MgF}_{2}$ Catalysts for the Fast and Selective Saccharification of Cellulose to Glucose, ChemSusChem, 2012, 5(9), 1708-1711.

37 S. Wuttke, G. Scholz, S. Rüdiger and E. Kemnitz, Variation of sol-gel synthesis parameters and their consequence for the surface area and structure of magnesium fluoride, J. Mater. Chem., 2007, 17(47), 4980-4988.

38 S. Wuttke, A. Vimont, J. C. Lavalley, M. Daturi and E. Kemnitz, Infrared Investigation of the Acid and Basic Properties of a Sol-Gel Prepared $\mathrm{MgF}_{2}$, J. Phys. Chem. C, 2010, 114(11), 5113-5120.

39 E. Kemnitz, S. Wuttke and S. M. Coman, Tailor-Made MgF2-Based Catalysts by Sol-Gel Synthesis, Eur. J. Inorg. Chem., 2011 (31), 4773-4794.

40 G. Scholz, D. Heidemann and E. Kemnitz, Local Structure of Nanoscopic Magnesium Hydroxide Fluorides Studied by Natural Abundance $25 \mathrm{Mg}$ Solid State NMR Spectroscopy, Z. Anorg. Allg. Chem., 2013, 639(5), 694-701.

41 S. Wuttke, S. M. Coman, G. Scholz, H. Kirmse, A. Vimont, M. Daturi, S. L. M. Schroeder and E. Kemnitz, Novel Sol-Gel Synthesis of Acidic $\mathrm{MgF}_{2-x}(\mathrm{OH})(\mathrm{x})$ Materials, Chem. - Eur. J., 2008, 14(36), 11488-11499.

42 O. V. Palashov, E. A. Khazanov, I. B. Mukhin, I. A. Mironov, A. N. Smirnov, K. V. Dukel'skii, P. P. Fedorov, V. V. Osiko and T. T. Basiev, Comparison of the optical parameters of a CaF2 single crystal and optical ceramicss, Quantum Electron. + , 2007, 37(1), 27-28.

43 (a) J. S. Wang, W. R. Miao, Y. X. Li, H. C. Yao and Z. J. Li, Water-soluble $\operatorname{Ln}(3+)$-doped calcium fluoride nanocrystals: Controlled synthesis and luminescence properties, Mater. Lett., 2009, 63(21), 1794-1796; (b) X. Y. Sun, M. Gu, S. M. Huang, X. J. Jin, X. L. Liu, B. Liu and C. Ni, Luminescence behavior of $\mathrm{Tb}^{3+}$ ions in transparent glass and glass-ceramics containing $\mathrm{CaF}_{2}$ nanocrystals, J. Lumin., 2009, 129(8), 773-777; (c) C. Feldmann, M. Roming and 
K. Trampert, Polyol-mediated synthesis of nanoscale $\mathrm{CaF}_{2}$ and $\mathrm{CaF}_{2}$ :Ce,Tb, Small, 2006, 2(11), 1248-1250.

44 B. Ritter, T. Krahl, K. Rurack and E. Kemnitz, Nanoscale $\mathrm{CaF}_{2}$ doped with $\mathrm{Eu}^{3+}$ and $\mathrm{Tb}^{3+}$ through fluorolytic sol-gel synthesis, J. Mater. Chem. C, 2014, 2(40), 8607-8613.

45 M. Ahrens, G. Scholz, M. Feist and E. Kemnitz, Application of an alkoxide sol-gel route for the preparation of complex fluorides of the $\mathrm{MAlF}_{4}(\mathrm{M}=\mathrm{K}, \mathrm{Cs}), \mathrm{M}_{3} \mathrm{AlF}_{6}(\mathrm{M}=\mathrm{Li}, \mathrm{Na}, \mathrm{K})$, and $\mathrm{Na}(5) \mathrm{Al}(3) \mathrm{Fl}(4)$ type, Solid State Sci., 2006, 8(7), 798806.

46 (a) M. A. F. M. da Silva, R. B. Barthem and L. P. Sosman, Investigation of luminescence and optical absorption of $\mathrm{K}_{2} \mathrm{LiAlF}_{6}: \mathrm{Cr}^{3+}$ single crystals, J. Solid State Chem., 2006, 179(12), 3718-3723; (b) G. A. Torchia, O. Martinez-Matos, N. M. Khaidukov and J. O. Tocho, Phonon coupling of $\mathrm{Cr}^{3+}$ ions in $\mathrm{Cs}_{2} \mathrm{NaAlF}_{6}$ crystals, Solid State Commun., 2004, 130(3-4), 159-163.

47 C. Stosiek, H. Ludwig, U. Reichel, G. Scholz and E. Kemnitz, Nanoscopic Metal Fluorides as Promising Sintering Aids for High-Performance Alumina Ceramics, J. Ceram. Sci. Technol., 2011, 2(1), 31-38.

48 W. Glaubitt and P. Löbmann, Antireflective coatings prepared by sol-gel processing: Principles and applications, J. Eur. Ceram. Soc., 2012, 32(11), 2995-2999.

49 D. Jacob, F. Peiro, E. Quesnel and D. Ristau, Microstructure and composition of MgF2 optical coatings grown on Si substrate by PVD and IBS processes, Thin Solid Films, 2000, 360(1-2), 133-138.

50 M. E. Fragala, R. G. Toro, S. Privitera and G. Malandrino, MOCVD Fabrication of Magnesium Fluoride Films: Effects of Deposition Parameters on Structure and Morphology, Chem. Vap. Deposition, 2011, 17(4-6), 80-87.

51 D. Ristau, S. Günster, S. Bosch, A. Duparré, E. Masetti, J. Ferré-Borrull, G. Kiriakidis, F. Peiró, E. Quesnel and A. Tikhonravov, Ultraviolet Optical and Microstructural Properties of $\mathrm{MgF}_{2}$ and $\mathrm{LaF}_{3}$ Coatings Deposited by Ion-Beam Sputtering and Boat and Electron-Beam Evaporation, Appl. Opt., 2002, 41(16), 3196-3204.

52 (a) T. Pilvi, T. Hatanpaa, E. Puukilainen, K. Arstila, M. Bischoff, U. Kaiser, N. Kaiser, M. Leskela and M. Ritala,
Study of a novel ALD process for depositing $\mathrm{MgF}_{2}$ thin films, J. Mater. Chem., 2007, 17(48), 5077-5083; (b) T. Pilvi, E. Puukilainen, U. Kreissig, M. Leskela and M. Ritala, Atomic layer deposition of $\mathrm{MgF}_{2}$ thin films using $\mathrm{TaF}(5)$ as a novel fluorine source, Chem. Mater., 2008, 20(15), 50235028.

53 (a) J. Hegmann and P. Löbmann, Sol-gel preparation of $\mathrm{TiO}_{2}$ and $\mathrm{MgF}_{2}$ multilayers, J. Sol-Gel Sci. Technol., 2013, 67(3), 436-441; (b) H. Krüger, E. Kemnitz, A. Hertwig and U. Beck, Transparent $\mathrm{MgF}_{2}$-films by sol-gel coating: Synthesis and optical properties, Thin Solid Films, 2008, 516(12), 4175-4177; (c) A. A. Rywak and J. M. Burlitch, Sol-gel synthesis of nanocrystalline magnesium fluoride: Its use in the preparation of $\mathrm{MgF}_{2}$ films and $\mathrm{MgF}_{2}-\mathrm{SiO}_{2}$ composites, Chem. Mater., 1996, 8(1), 60-67.

54 P. Ericsson, S. Bengtsson and U. Sodervall, Influence of Prebonding Cleaning on the Electrical-Properties of the Buried Oxide of Bond-and-Etchback Silicon-on-Insulator Materials, J. Appl. Phys., 1995, 78(5), 3472-3480.

55 (a) D. Bernsmeier, J. Polte, E. Ortel, T. Krahl, E. Kemnitz and R. Kraehnert, Antireflective Coatings with Adjustable Refractive Index and Porosity Synthesized by Micelle-Templated Deposition of $\mathrm{MgF}_{2}$ Sol Particles, ACS Appl. Mater. Interfaces, 2014, 6(22), 19559-19565; (b) J. Noack, K. Teinz, C. Schaumberg, C. Fritz, S. Rüdiger and E. Kemnitz, Metal fluoride materials with complex pore structure and organic functionality, J. Mater. Chem., 2011, 21(2), 334338.

56 J. Noack, C. Fritz, C. Flügel, F. Hemmann, H. J. Gläsel, O. Kahle, C. Dreyer, M. Bauer and E. Kemnitz, Metal fluoride-based transparent nanocomposites with low refractive indices, Dalton Trans., 2013, 42(16), 5706-5710.

57 C. Fritz, G. Scholz, M. Feist and E. Kemnitz, Preparation and stabilization of aluminium trifluoroacetate fluoride sols for optical coatings, Dalton Trans., 2012, 41(37), 11351-11360.

58 J. Noack, L. Schmidt, H. J. Gläsel, M. Bauer and E. Kemnitz, Inorganic-organic nanocomposites based on sol-gel derived magnesium fluoride, Nanoscale, 2011, 3(11), 4774-4779. 